\title{
WHY “BAD” PATENTS SURVIVE IN THE MARKET AND HOW SHOULD WE CHANGE? - THE PRIVATE AND SOCIAL COSTS OF PATENTS
}

\author{
Jay P. Kesan * \\ Andres A. Gallo**
}

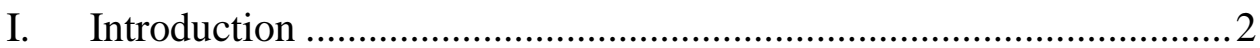

II. Patent Reform Proposals .............................................................. 7

III. Incorrectly Issued Patents and Patent Office Incentives ..................10

A. How do Incorrectly Granted Patents Survive in the Market?........11

B. Changes in Litigation Costs......................................................19

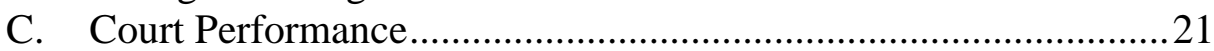

D. Private Transaction Costs ........................................................23

IV. Reforming the Patent Office With Post-Issuance Challenges .......25

A. The Model....................................................................................22

B. Characteristics of the New System ................................................33

C. Pre-grant or Post-grant Procedure ................................................ 34

D. Scope of the Estoppel and Type of Procedure..............................36

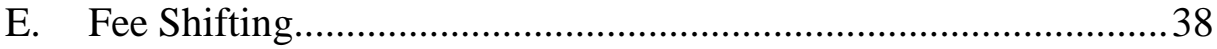

V. Recent Evidence from Japan: Dual Patent Invalidation

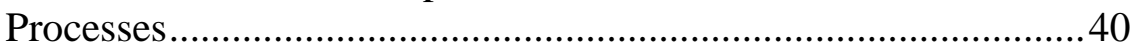

VI. Conclusions ........................................................................ 44

VII. Appendix A.................................................................. 46

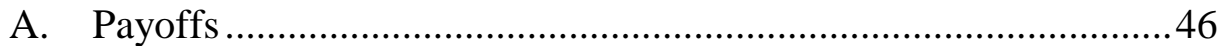

B. Static Comparative ..................................................................49

VIII. Appendix B .....................................................................54

*Professor \& Director, Program in Intellectual Property \& Technology Law, University of Illinois College of Law. Jay Kesan would like to acknowledge the generous financial assistance of the Institute of Intellectual Property (IIP) in Tokyo, Japan when he was an Invited Foreign Researcher at IIP. Much of the empirical data presented in this work was gathered with the assistance of the researchers at IIP and the patent examiners in the International Division at the Japanese Patent Office (JPO). This work has also benefited from the comments and suggestions of participants at the First Annual Intellectual \& Communications Law and Policy Conference at Michigan State University, the Law and Society Annual Meeting, the Midwest Law and Economics Association Meeting, and law faculty workshops at Boston University, University of North Carolina, DePaul University, University of San Diego, University of Tokyo, and the Institute of Intellectual Property (IIP) in Tokyo, Japan. Jay Kesan would also like to acknowledge the able research assistance of Thayer Marie Preece.

${ }_{* *}^{* *}$ Assistant Professor, Department of Economics, University of North Florida. 


\section{INTRODUCTION}

The United States Patent and Trademark Office (the "Patent Office" or "USPTO") has recently come under increasing scrutiny for the quality of the examinations to which patent applications are subjected. ${ }^{1}$ It has been urged that U.S. patent examination is deficient when compared with international patent offices. ${ }^{2}$ The common criticism from all sides is that the Patent Office grants patent claims that are broader than what is merited by the invention and the prior art, resulting in so-called "bad" (i.e., improvidently granted) patents. ${ }^{3}$ These problems are particularly important for new technologies like Internet and computer software, where it can be difficult to identify prior art information. ${ }^{4}$ The existence of these types of errors has important economic consequences, including the generation of inefficient resource allocation and significant harm to economic growth. ${ }^{5}$

1. See generally Joseph Scott Miller, Building a Better Bounty: Litigation-Stage Rewards for Defeating Patents, 19 BerKeley TeCH L.J. 667 (2004); F. Scott Kieff, The Case for Registering Patents and the Law and Economics of Present Patent-Obtaining Rules, 45 B.C. L. REV. 55 (2004); Jay P. Kesan, Carrots and Sticks to Create a Better Patent System, 17 BERKELEY TeCH L. J. 763 (2002); Mark A. Lemley, Rational Ignorance at the Patent Office, 95 Nw. U. L .REV. 1495 (2001); Robert P. Merges, As Many As Six Impossible Patents Before Breakfast: Property Rights for Business Concepts and Patent System Reform, 14 BERKELEY TECH. L.J. 577 (1999); John R. Thomas, Collusion and Collective Action in the Patent System: A Proposal for Patent Bounties, 2001 U. ILl. L. Rev. 305 (2001); Allen M. Leung, Legal Judo: Strategic Applications of Reexamination Versus an Aggressive Adversary (Part I), 84 J. PAT. \& TRADEMARK OFF. SOC'Y 471 (2002); John Thomas, The Responsibility of the Rulemaker: Comparative Approaches to Patent Administration Reform, 17 BERKELEY TECH. L.J. 727 (2002); John Allison \& Mark Lemley, The Growing Complexity of the United States Patent System, 82 B. U. L. REV. 77 (2002); Cecil Quillen Jr. \& Webster Ogden, Continuing Patent Applications and Performance of the U.S. Patent and Trademark Office, 11 FeD. CIRCUIT B.J. 1 (20012002); Kevin Baird, Business Method Patents: Chaos at the USPTO or Business as Usual? 2001 J. L. TECH. \& POL'Y 347 (2001); Craig Allen Nard, Symposium: Intellectual Property Challenges in the Next Century: Process Considerations in the Age of Markman and Mantras, 2001 U. ILL. L. REV. 355 (2001); Arti K. Rai, Symposium: Ideas into Action: Implementing Reform of the Patent System: Allocating Power over FactFinding in the Patent System, 19 BERKELEY TeCH. L.J. 907 (2004); Arti K. Rai, Engaging Facts and Policy: A Multi-Institutional Approach to Patent System Reform, 103 ColuM. L. REV. 1035 (2003); Dan L. Burk \& Mark A. Lemley, Policy Levers in Patent Law, 89 VA. L. REV. 1575 (2003); Rebecca S. Eisenberg, Symposium: Ideas into Action: Implementing Reform of the Patent System: Obvious to Whom? Evaluating Inventions from the Perspective of PHOSITA, 19 BERKELEY TECH. L.J. 885 (2004); and Rochelle Cooper Dreyfuss, Technology and the Arts Symposium: The Past, Present and Future of the Federal Circuit: The Federal Circuit: A Continuing Experiment in Specialization, 54 CASE W. RES. L. REV. 769 (2004).

When referring to the United States Patent \& Trademark Office, we generally use the term Patent Office instead of PTO or USPTO to make clear that we are referring to the patent-related activities of the USPTO.

2. "[I]t is evident that examination of patent applications by the PTO (US Patent Office) is significantly less rigorous than is the examination of patent applications by the EPO (European Patent Office), the JPO (Japanese Patent Office), or the GPO (German Patent Office). Also, the likelihood of ultimately obtaining allowance of a patent application from the PTO is far higher than in the EPO, the JPO, or the GPO." Quillen \& Webster, supra note 1 , at 13.

3. See e.g., Miller, supra note 1, at 669; Kesan, supra note 1, at 763-64

4. See Julie E. Cohen, Reverse Engineering and the Rise of Electronic Vigilantism: Intellectual Property Implications of Lock-Out Technologies, 68 S. CAL. L. REV. 1091, 1178 (1995) (claiming that for patents on computer software, prior art is found outside the areas in which the Patent Office traditionally conducts searches).

5. See generally Kesan, supra note 1, at 149-150; Andrew Horowitz and Edwin L.-C. Lai, Patent Length and the Rate of Innovation, 37 INT'L ECON. R. 4, 785-801 (1996) (studying the impact of patent length over the rate of innovation and consumer welfare). See also Roberto Mazzoleni \& Richard Nelson, The Benefits and Costs of Strong Patent Protection: A Contribution to the Current Debate, 27 RESEARCH POL'Y 
The response from legal scholars interested in patent reform has been vigorous and sustained. ${ }^{6}$ Proposing and perfecting patent bounties, ${ }^{7}$ considering a registration system for patents, ${ }^{8}$ introducing fee shifting and other patent litigation reform such as changing evidentiary standards, ${ }^{9}$ and proposing new administrative processes such as patent oppositions, ${ }^{10}$ are just some of the many serious proposals that have been advanced.

It is a richly satisfying time to be studying patent reform and patent institutional reform both in the United States and, in a comparative sense, countries such as Japan. In the U.S., we have the USPTO's 21st century Strategic Plan proposing various patent reform measures, and the Federal Trade Commission ("FTC") recently held extensive hearings on Competition and Patent Law and Policy, producing a detailed report outlining many areas for patent reform. Both efforts conclude that serious consideration must be given to creating post-grant administrative procedures in the USPTO to challenge issued patents.

In Japan, there are efforts to embark on a pro-patent policy, including the creation of a Strategic Program for the Creation, Protection and Exploitation of Intellectual Property, with an IP Policy Headquarters that has outlined its set of new initiatives. In addition, after the Kilby decision by the Supreme Court of Japan in April 2000, there is now a dual track invalidation system in Japan invalidation of patents through invalidation trials in the Japanese Patent Office ("JPO"), and invalidation by the District Courts through the so-called "abuse of patent right" (not to be confused with patent misuse doctrine) in cases where patents that are obviously invalid are asserted in litigation. ${ }^{11}$ Finally, there is a merger of oppositions and trials for invalidation in the JPO starting this year. In short, invalidation procedures in Patent Offices or in the courts are a hot topic and worthy of careful consideration and our best efforts.

Most of the studies of the patent system conducted by economists assume that the agency in charge of granting and managing the system functions with perfect efficiency, i.e., there are no transaction costs imposed by the patent system. ${ }^{12}$ Thus, the patent acquisition and enforcement system, as a whole, is a black box that works perfectly. In practice, however, the Patent Office has been subject to harsh criticism over its procedure for granting patents. ${ }^{13}$ First, the Patent Office's process for reviewing patent applications may not involve an adequate search for relevant prior art in different technological fields. ${ }^{14}$ Compared with

273 (1998) (analyzing the impact of patent protection over investment and economic progress, the authors claim that a high level of protection can hinder technological advances and economic growth.).

6. See references supra note 1.

7. See generally Thomas, supra note 1 ; Miller, supra note 1.

8. See Kieff, supra note 1 .

9. See Kesan, supra note 1 .

10. See Merges, supra note 1; Kesan, supra note 1.

11. See infra notes 134132 The term "abuse of patent right" is not similar or related to the patent misuse doctrine in the U.S. This term simply refers to patent invalidation in the courts in Japan. In this context, the term "invalidation" is not used because patent validity is purely a matter for the JPO under Japanese Patent Law. Hence, the Japanese Supreme Court in the Kilby decision chose to refer to patent invalidation by the courts as arising from an abuse of the patent right that required correction by the courts.

12. For a good exception to this kind of study, see Carl Shapiro, Antitrust Limits to Patent Settlements, 34 RAND J. OF ECON. 391 (2003). See also infra notes 51-57.

13. See supra note 1 and accompanying text.

14. See Kesan, supra note 1, at 147-148.

"The real problem can be summarized by a 1999 survey conducted by Greg Aharonian, which revealed that fifty percent of all patent applications cited no prior art at all. Mr. Aharonian similarly estimates that 
other patent offices like those in Japan and the European Union, it is urged that the USPTO has high rates of acceptance and low levels of review. ${ }^{15}$ Second, the USPTO is not free from political influence. Important interest groups that exert pressure on policymakers in Congress and the USPTO directly shape patent policy. ${ }^{16}$ Finally, the laws and regulations that dictate the behavior of the USPTO do not provide the correct incentives needed to grant valid patents. ${ }^{17}$ For example, the USPTO receives a fee for each issued patent, without penalties for incorrectly issued (this article uses "bad" interchangeably with "incorrectly issued") patents. Furthermore, the Patent Office knows that the courts function as a safety net by overturning incorrectly issued patents that are commercially significant. ${ }^{18}$ Consequently, there are no incentives for the USPTO to develop efficient mechanisms to avoid issuing incorrect patents, thus avoiding subsequent social costs. ${ }^{19}$ As we will show in the next few paragraphs, in practice, not only are there very significant transaction costs associated with the patent system, they also induce inefficient strategic behavior by firms and individuals.

The rate at which the Patent Office issues patents has increased in recent years. ${ }^{20}$ Correspondingly, the number of patents issued involving high technology and Internet markets has increased dramatically. ${ }^{21}$ A major characteristic of some

somewhere between fifty percent and seventy percent of software patents would likely not issue if the examiners were to conduct prior art searches of both Patent Office archives and databases that are readily available but not accessible within the confines of the Patent Office." Eugene Quinn Jr., The Proliferation of Electronic Commerce Patents: Don't Blame the PTO, 28 Rutgers UnIV. COMP. \& TECH. L.J. 121, 121 (2002).

15. "From the foregoing, it is evident that the examination of patent applications by the PTO [U.S. Patent \& Trademark Office] is significantly less rigorous than is the examination of patent applications by the EPO [European Patent Office], the JPO [Japan Patent Office], or the GPO [Germany Patent Office]. Also, the likelihood of ultimately obtaining allowance of a patent application from the PTO is far higher than in the EPO, the JPO, or the GPO." Quillen \& Webster, supra note 1, at 13.

16. See Michael H. Davis, Patent Politics, SSRN WORKING PAPER (September 2001), at http://papers.ssrn.com/ sol3/papers.cfm?abstract_id=282056 (explaining the political determinants of the U.S. patent system characteristics).

17. See references supra note 1 .

18. "In contrast to our surgeon, the USPTO bears no responsibility for allowing an invalid patent to issue. Courts do not fine the USPTO upon invalidating a patent; the examiners who allowed the case are not disciplined for their oversight; nor must the USPTO award damages to affected members of the public to compensate for an improvidently granted patent. The costs of failing to acquire information are simply shifted to the other actors -in particular, the federal courts, the patentee's competitors, and ultimately, the consumers." Thomas, supra note 1 , at 733 .

19. "[B] usiness methods and data transformation patents concern information rather than industrial products. Such products tend to exhibit lock-in and network externalities. Lock-in occurs when consumers face high costs in switching from one brand of technology to another. Network externalities result from a situation of positive feedback, where the value of connecting to a network depends upon the number of other people also connected to the network. Applied to economic competition, the typical result of network effects is a monopolistic, winner-take-all market. Telephony and computer operating systems present examples of markets with network externalities. These economic characteristics of information products suggest that software and business method patents need not to be considered valid for a long period in order to have substantial market impact." Id. at 320.

20. See references supra note 1 .

21. "Many of the more recent financial software patents comprise algorithms executing steps for a specific "business method" which is a simple algorithm that can be practiced without the use of a computer system. There is another traditional prohibition at the U.S. Patent Office against the patenting of business methods. When applications were previously filed claiming financial software, the Patent Office rejected the application not only for being a mathematical expression, but also for being a business method per se. Some in the software industry foresaw a sea change in the U.S. patent law that would lead to the patenting of software. 
of these sectors is that they are not areas of traditional patenting. ${ }^{22}$ As Allison and Lemley demonstrated, the type and complexity of patents have changed over the last decade, and this has made it more difficult for the Patent Office examiners to decide which patents should issue. ${ }^{23}$ The experience of the Patent Office in examining some of these types of patents is virtually nonexistent, thereby increasing the chance of error. ${ }^{24}$ Furthermore, examiners' incentives are not conducive to good review of patent applications. ${ }^{25}$ As a result, changes in the type and technological complexity of patents requested from the Patent Office, coupled with the lack of appropriate incentives, increase the possibility of making mistakes by issuing new patents. ${ }^{26}$ For example, patents issued for Internet business methods have produced many claims of obviousness. ${ }^{27}$ It is then not altogether surprising that the Patent Office grants numerous patents for which compliance with the novelty and non-obviousness patentability requirements are questionable, ${ }^{28}$ creating excessive burdens on society. ${ }^{29}$

Judicial review is one of the traditional remedies for correcting improperly issued patents. ${ }^{30}$ Firms and individuals do try to avoid or minimize the cost of

Even so, the main prohibitions against patenting software, especially financial software, were clearly removed by the U.S. Court of Appeals for the Federal Circuit and its 1998 decision of State Street Bank \& Trust Co., v. Signature Financial Group, Inc., 149 F.3d 1368, 47 USPQ2d 1596 (Fed. Cir. 1998).” Lance D. Reich, Dot.Com (Patent Pending): Patents Are Now Central to Business Strategy, 75 MAR. Fla. B. J. 42, 42 (2001). See also United States Patent \& Trademark Office, USPTO Business Plan, United States Patent \& TRADEMARK OFFICE 9, at http://www.uspto.gov (February 2002) (showing the growth in patent and trademark applications during the last decade).

22. "[W]ith industry routinely seeking patent protection for gene sequences, software, business methods, and other postindustrial inventions, the number of stakeholders in the patent system has greatly expanded in recent years." Thomas, supra note 1 , at 316 .

23. See John R. Allison \& Mark A. Lemley, The Growing Complexity of the United States Patent System, 82 B.U.L. REV. 77, 78-141 (2002).

24. "Another problem at the USPTO that has increased the difficulty in examining business method patent applications is the lack of examiners with backgrounds in business and business methods. Typically, examiners have expertise in technical fields such as engineering or biotechnology; however, they often lack business backgrounds and knowledge. The USPTO has been slow to hire examiners with business backgrounds despite the large increase in business method patent applications." Baird, supra note 1, at 355.

25. "Additionally, Patent Office practice requires that examiners articulate their reasons for rejection, while most often examiners need say nothing if they chose to allow the case. The belief is widely held that this regime encourages examiners to allow rather than to reject applications." Thomas, supra note 1, at 324-325.

26. See John R. Allison \& Mark A. Lemley, Empirical Evidence on the Validity of Litigated Patents, 26 AIPLA Q. J. 185 (1998) (finding that just 54\% of the patents contested in court were found as valid).

27. See David Schumann, Obviousness with Business Methods, 56 U. MIAMI L. REV. 727 (2002) (describing different examples of business method patenting in the Internet, which are simple adaptations of real life methods to the Internet, without any original invention).

"Business method patents may also provide a vehicle for raising much needed start-up capital. Patents are becoming a critical factor in valuing many new economy businesses. In contrast, because of strong 'network effects' in high technology industries, large companies may be able to undermine the entry of potential competitors by obtaining business method patents... [S]trong patent protection can create insurmountable barrier[s] to entry while also allowing a single patentee to direct innovation in the market. The importance of these effects may be especially acute in the area of software applications and Internet technologies. The recognition of business method patents presents at least the potential for such anti- competitive effects." Larry A. DiMatteo, The New Problem of Business Method Patents: The Convergence of National Patent Laws and International Internet Transactions, 28 RUTGERS COMPUTER \& TECH. L. J. 1, 22-23 (2002).

28. See John Kasdan, Obviousness and New Technologies, 10 FordHAM InTELl. Prop. Media \& EnT. L. J. 159 (1999) (describing the problems of the USPTO in detecting obviousness in new technology patent requests). See also Allison and Lemley, supra note 27 (describing how prior art and obviousness are the main factors mentioned in court for challenging the validity of patents).

29. See Allison \& Lemley, supra note 26 (showing evidence on the lack of validity of patents granted by the Patent Office and contested in courts).

30. "It is not surprising, therefore, that the PTO issues many patents that would have been rejected had the examiner possessed perfect knowledge. This is particularly true since much of the most relevant prior art 
patent litigation, since these litigation costs are very high. ${ }^{31}$ The cost of going to court also discourages challenges to incorrectly issued patents. ${ }^{32}$ Indeed, it is suggested that many firms may be discouraged from using the legal system. ${ }^{33}$ In fact, even when the patent is not valid, using the courts may be more expensive than both licensing costs and the transaction costs of bargaining required to reach a private agreement.

Considering the cost of litigation and the probability of getting a patent issued by the Patent Office, it is often optimal for inventors to look for inventions which have a likelihood of being patented. ${ }^{34}$ As a result, we should expect the Patent Office to be flooded with patent applications, furthering inefficient management of the agency. We should also expect firms to implement strategic behavior that aims to achieve market control through easily obtainable patents, such as improving market competitiveness by either creating an advantage through proprietary inventions or thwarting competitors' inventions. ${ }^{35}$ It is likely that firms will develop different sophisticated strategies to control industry standards and the investment activities of their competitors. ${ }^{36}$ In sum, the transaction costs

isn't easy to find-it consists of sales or uses by third parties that don't show up in any searchable database and will not be found by examiners in a hurry. Indeed, in litigated cases that actually result in a final judgment on validity, issued patents are held invalid forty-six percent of the time." Lemley, supra note 1, at 1500.

31. "Anyone who has ever been involved in a patent infringement lawsuit knows that "patent litigation is a very costly process." Attorneys and experts must be hired and associated litigation costs are incurred. According to a 1999 study by the Intellectual Property Law Association, the median total cost through the end of suit for patent litigation where the dollar amount at risk is $\$ 10-\$ 100$ million is $\$ 2,225,000$. Just to take the case through discovery costs $\$ 1,491,000$.

The costs of litigation to parties involves more than the costs of retaining attorneys and experts and paying for court costs, copying expenses, and transcripts. Litigation also drains away firm resources by requiring managers and other employees to focus time and attention on the litigation, instead of ordinary firm business. For every hour that a lawyer spends preparing for, taking, or defending a deposition, the client often spends an hour in fact-gathering or being deposed.

Patent litigation imposes costs not only on parties, but also on courts. For every incremental dollar spent in litigation by the litigants, additional costs are often incurred by the judicial system as well. Thus, a rule that requires parties to litigate instead of settling thus imposes substantial direct costs on the court system and on the taxpayers who fund the system." Daniel Crane, Exit Payments in Settlement of Patent Infringement Lawsuits: Antitrust Rules and Economic Implications, 54 FLA. L. REV. 747, 757 (2002).

32. "Although they[bad patents] are prone to attacks on their validity, bad patents may nevertheless deter meritorious challenges: "[S]mall companies may not be willing to invest resources in such a challenge, especially with the presumption of validity that attends PTO decisions. Rather, it may make more sense for these companies to accept a license fee from the patentee, thereby leaving the inappropriate patent unchallenged." DiMatteo, supra note 27, at 23.

33. Id.

34. Id. (analyzing the incentives for patenting new technology in the Internet).

35. "Many of the reasons for the surge of patents in the software and Internet area are straightforward. One major reason is that a recent change in U.S. case law has allowed the business methodology underlying the software's function to be patented. Another significant reason comes from the shifting economy and the increasing dominance of e-commerce and its associated software and Internet applications.

However, other less obvious factors are also motivating the increased patent filings. The venture capital arena is quite savvy to the importance of an intellectual property portfolio. Further, the increasing publicity of recent Internet and software patents and patent-related litigation has heightened awareness of the combative patent arena and has business management clamoring to obtain their patent swords and shields." Reich, supra note 21 , at 42.

36. Some of the patenting strategies followed by firms are: "Blanketing'. Efforts are made to turn an area into a jungle or a minefield of patents, for example, 'mining' or 'bombing' every step in a manufacturing process with patents, more or less systematically.

'Flooding' is a less structured way of taking out multiple patents, major as well as minor, in a field and may result from patenting-reward schemes as much as from a conscious strategy. 
associated with the patent system are very significant, and they encourage inefficient strategic conduct.

In this paper, we formally demonstrate that incorrectly issued patents can survive in the market without judicial review, even when the invention is neither novel nor non-obvious. We support this contention by presenting a game theoretic model that studies the interaction between the patentee and an alleged infringer/challenger. Using this model, we demonstrate the impact of the transaction costs in the patent system at the administrative stage in the Patent Office and at the enforcement stage in the courts, and highlight the inability in our current system to mount effective challenges to improperly granted patents in the current system. We also evaluate how changes in patent litigation costs and the quality of adjudication in the courts affect the incentives to challenge patents thereby affecting the probability of securing a patent. We show that there is a need to advance new mechanisms to improve the administrative processes employed by the Patent Office.

Specifically, we support including administrative challenges, such as patent oppositions, in order to improve Patent Office functioning by correcting and limiting the number of improperly granted patents. We describe and analyze the characteristics of such an opposition system, including the costs of such a process, the timing of the process with respect to patent issuance, and the scope of the estoppel granted to such a process for both subsequent oppositions and court challenges to the patent. We conclude that a low-cost, post-grant, opposition process based primarily on written submissions with a limited estoppel effect and administered by Administrative Opposition Judges (AOJs) will serve as an effective instrument for improving the quality of patents that are issued and enforced. In other words, including these incentives for producing better quality patents will decrease the number of incorrectly issued patents. These incentives will improve overall social welfare thereby reducing the incentives for strategic conduct and aggressive patenting in many technology areas. Broadly speaking, this work is in the same vein as other works by Professor Craig Nard and Professor Arti Rai addressing administrative reform involving the Patent Office and the relationship between the Patent Office and the courts.

Finally, we present empirical results from an exciting patent reform "experiment" taking place in Japan in the past four years and compare these results to the insights obtained from our model. Since April 2000, Japan has embraced a dual patent invalidation system that permits patent challenges in both the Japanese Patent Office (JPO) and their District Courts. Our empirical data on dual invalidation processes in Japan from 2000-2003 demonstrate that there are sound economic and institutional reasons for maintaining the ability to raise patent

'Fencing'. This refers to the situation where a series of patents, ordered in some way, block certain lines or directions of $R \& D$, for example, a range of variants of a chemical sub-process, molecular design, geometric shape, temperature conditions or pressure conditions.

'Surrounding'. Typically this is the case when an important central patent of some kind, especially a strategic patent, can be fenced in or surrounded by other patents, which are individually less important but collectively block the effective commercial use of the central patent, even after its expiration. Often, surrounding patents pertain to different applications of a basic invention.

'Combination into patent networks.' This refers to the building of a patent portfolio in which patents of various kinds and configurations are consciously used to strengthen overall protection and bargaining power." Carlos Correa, Internationalization of the Patent System and New Technologies, 20 WIS. INT'L L. J. 523,537 (2002). 
validity challenges in both the Patent Office and the courts. Indeed, the results of the experiment in Japan show that there are sound economic and institutional reasons for maintaining both patent invalidation processes since both mechanisms are complementary and necessary.

\section{PATENT REFORM PROPOSALS}

A number of techniques for reforming the patent system have been proposed by scholars and other organizations. One of the prevailing strategies for patent system reform is the introduction of bounties. Professor John R. Thomas suggests that examination-stage bounties are an optimal tool for patent system reform. Because third parties generally have little incentive to bring prior art to the attention of the Patent Office, bounties would reward otherwise uninterested parties for providing pertinent information. In addition, bounties would encourage applicants to provide greater disclosures by fining applicants who do not disclose prior art that is later disclosed by a third party. The use of anonymity would encourage candid disclosures from all sides. In addition, by turning the general public into supplemental patent examiners, this system would decrease the burden on the Patent Office. ${ }^{37}$ Professor Joseph Scott Miller proposes a similar bounty scheme, except he proposes that bounties should be available at the litigation stage. If a challenger defeats a patentee in litigation, the patentee would pay a bounty to the successful challenger. The bounty would only be available in cases where the invalidation was based on grounds that could have been prevented by increased diligence and candor on the part of the patentee in his application. This system would increase disclosure and care on the part of patent applicants, and it would provide for bounties in cases where patents were overturned for reasons other than prior art. ${ }^{38}$

Professor F. Scott Kieff proposes that a registration system, as opposed to an examination system, should be used to grant patents. Because the costs of a more thorough examination would be greater than those of litigation, a registration system would shift costs away from the Patent Office and the public, and towards those with a commercial interest in the patent. A very small number of patents are actually commercially viable, yet currently all are examined. By switching to a registration system, only those patents that are commercially significant would incur costs for verification of validity. ${ }^{39}$

Professor Robert P. Merges suggests several techniques for streamlining the patent application process. First, he would redesign the examiner job structure, paying senior examiners more, and spending more time on training junior examiners. This reform would also include redesigning the bonus system for examiners, paying bonuses for those examiners who have low error rates. Finally, Professor Merges would institute a patent opposition procedure that allows more thorough reexaminations. This procedure would include participation by the thirdparty opposition, appeals from adverse decisions, and preventing patentees from

11. See generally Thomas, supra note 1 .

38. See generally Miller, supra note 1.

39. See generally Kieff, supra note 1. 
using a stay of litigation during reexamination for strategic delay. ${ }^{40}$

Other scholars turn to the European Union for guidance, Professors Bronwyn H. Hall, Stuart J. H. Graham, Dietmar Harhoff, and David C. Mowery propose a system of post-grant opposition procedures modeled off of the EU's system to reform the US patent system. They analyze the costs and benefits of such a system and conclude that the post-grant opposition procedure would encourage disclosure of prior art, decrease the amount of time necessary to establish a patent's validity, and increase the quality of patents that are granted. ${ }^{41}$ These authors based their research in part on a comparative study they performed of patent oppositions in Europe and re-examination proceedings in the U.S. ${ }^{42}$

Professor Mark D. Janis also turned to the EU for inspiration when advocating a new administrative revocation scheme as an alternative to costly litigation. Professor Janis contends that the best course of action would be to scrap the current re-examination system and adopt an inter partes administrative revocation system based on European practice and U.S. trademark procedures. ${ }^{43}$

Professors John R. Allison, Mark A. Lemley, Kimberly A. Moore, and R. Derek Trunkey recently performed a study concerning the relatively miniscule enforcement rates among patent holders. They concluded that very few patents are enforced through litigation due to the fact that there is a small class of disputed patents that are inherently more valuable than the others. ${ }^{44}$ In his own article, Professor Lemley speculates that because very few patents are enforced through litigation, it is not worth improving patent office review, as such reform would cost more than what is currently spent on litigation. Instead, the courts should make a more thorough validity determination for those patents that are litigated, and the presumption of validity given to patents should be abolished. ${ }^{45}$

Patent reform has not been limited to scholarly debate. In 2004, a bill was introduced to the House of Representatives to try and reform the patent system. ${ }^{46}$ Entitled the "Patent Quality Assistance Act of 2004,"47 the proposed Act would have introduced new post-grant opposition procedures that would have allowed interested parties to present oppositions to issued patents within nine months of the patent issuance date. ${ }^{48}$ Although the bill did not become law, it demonstrates that the legislature has been considering options for patent system reform.

In addition, administrative entities have taken an interest in the patent reform debate. The National Research Council, of the National Academies, has recently published a work examining the current state of the patent system and suggesting

40. See generally Merges, supra note 1 .

41. Bronwyn H. Hall, Stuart J. H. Graham, Dietmar Harhoff \& David C. Mowery, Prospects for Improving U.S. Patent Quality Via Post-Grant Opposition, Working Paper 9731, NBER Working Paper Series (2003), available at http://www.nber.org/papers/w9731.

42. Stuart J. H. Graham, Bronwyn H. Hall, Dietmar Harhoff \& David C. Mowery, Post-Issue Patent "Quality Control": A Comparative Study of US Patent Re-examinations and European Patent Oppositions, Working Paper 8807, NBER Working Paper Series (2002), available at http://www.nber.org/papers/w8807.

43. Mark D. Janis, Rethinking Reexamination: Toward a Viable Administrative Revocation System For U.S. Patent law, 11 HARV. J.L. \& TECH. 1 (1997).

44. John R. Allison, Mark A. Lemley, Kimberly A. Moore \& R. Derek Trunkey, Valuable Patents, 92 GEO. L.J. 435 (2004).

45. Mark A. Lemley, Rational Ignorance at the Patent Office, 95 Nw. U.L. REV. 1495 (2001).

46. H.R. 5299, $108^{\text {th }}$ Cong. (2004).

47. Id. $\S 1$.

48. Id. $\$ 322-23$. 
methods for improving the system in the 21 st Century. ${ }^{49}$ The Council's recommendations for reforming the patent system include keeping the system open to new technologies, strictly enforcing the non-obviousness standard, introducing a post-grant review procedure, increasing USPTO resources, allowance of noncommercial uses (such as academic research) of patented technologies, litigation reform, and harmonization of the U.S. patent laws with those of the E.U. and Japan. $^{50}$

In economic discussions of patent law and policy, scholars have primarily concentrated on the effects patents have on markets and economic welfare. ${ }^{51}$ Most economic analyses of patent systems concentrate on three main areas of study. First, the existence of patent systems provides incentives for investing in research and development ("R\&D") by allowing the inventor to enjoy a monopoly on the product, device, or process invented. ${ }^{52}$ A patent system, therefore, generates shortterm inefficiencies, by providing monopoly power to the patentee. The same patent system also generates a long-term incentive to invest in R\&D by protecting the resources devoted to developing inventions. ${ }^{53}$ This research concentrates, for example, on the optimal length of a patent that minimizes monopoly effects and fosters investment. ${ }^{54}$ Second, economists have also studied the incentives that patent systems generate as compared to other forms of rewarding innovation. ${ }^{55}$ As an example of this area of research, because patents are granted to the first person who invents and files the patent claim, investors and inventors have a strong incentive to speed up their development process. This results in a "patent race" in which inventors accelerate their development in order to predate other inventors in claiming a specific invention. ${ }^{56}$ Finally, other studies analyze the impact of patents on economic development, industry growth, and strategic behavior among users and firms holding patents. ${ }^{57}$

49. National Research Council of the National ACAdEMIES, A Patent System for the 21st CENTURY (2004).

50. Id. at 81-83.

51. See generally Gregory Werden, Luke Froeb \& Lucian Beavers, Economic Analysis Lost Profits from Patent Infringement With and Without Noninfringing Substitutes, 27 AIPLA QUARTERLY JOURNAL, 305 (1999); R. Gilbert and C. Shapiro, Optimal Patent Length and Breadth, 21 RAND J. ECON., 106 (1990); H. F. Chang, Patent Scope, Antitrust Policy and Cumulative Innovation, 26 RAND J. ECON., 34 (1995); Roberto Mazzoleni and Richard Nelson, Economic Theories about the Benefits and Costs of Patents, XXXII J. OF ECON. Issues No. 4, 1031 (1998); Lerner, Joshua, The Importance of Patent Scope: An Empirical Analysis, 25 RAND J. ECON. 319 (1994); Pamela Samuelson \& Suzanne Scotchmer, The Law and Economics of Reverse Engineering, 111 YALE L. J., 1575 (2002); Andrew Horowitz \& Edwin Lai, Patent Length and the Rate of Innovation, 37 INT'L ECON. REV. 785 (1996).

52. See Nuno Pires de Carvalho, The Primary Function of Patents, 2001 J. L. TECH. \& POL'Y 25 (2001) (explaining the characteristics of patents and the cases in which they become actual monopolies, as they are known in the economic theory); see also Mazzoleni \& Nelson, supra note 5.

53. See generally Gilbert \& Shapiro, supra note 51; Mazzoleni \& Nelson, supra note 5.

54. See generally Horowitz \& Lai, supra note 5.

55. See Jean Tirole, The Theory of Industrial Organization, Chapter 10 (The MiT Press, 1990) (detailing in chapter 10 all the incentives generated by the existence of patents).

56. Id. at 394. See Bronwyn Hall \& Rose Marie Ham, The Patent Paradox Revisited: Determinants of Patenting in the US Semiconductor Industry, 1980-94, NBER WORKING PAPER 7062 (1999) (analyzing how the change in the importance of patents in the semiconductor industry created the incentives for patent portfolio races among industry firms).

57. See TIROLE, supra note 55, Chapter 10. 


\section{INCORRECTLY ISSUED PATENTS AND PATENT OFFICE INCENTIVES}

The Patent Office has an incentive to grant patents without being unduly concerned about the quality of its examination process. ${ }^{58}$ The existence of improperly granted patents is especially common in high technology sectors such as software and the Internet. ${ }^{59}$ In the Internet and software industry, several factors play an important role in producing "bad" patents. The Internet is an economic sector in which new processes and technologies appear frequently. ${ }^{60}$ As a result, many of the new patent claims come from arenas in which the Patent Office has little prior experience. ${ }^{61}$ These high technology patents tend to be more complex, requiring further research in order to determine their validity. ${ }^{62}$ Although the number of patent claims is increasing, examiners do not devote more time for studying the prior art. ${ }^{63}$ The introduction of improperly granted patents has important consequences for short-term market functioning and long-term investment.

In this section, we analyze two important problems generated by poor quality patents. Contrary to the implicit assumption by the PTO that "bad" patents can simply be contested in the courts, we demonstrate that most incorrectly issued patents are not necessarily going to be contested in the courts. On the contrary, incorrectly issued patents can survive in the marketplace and impose long-term welfare costs on society. Thus, the patent system's sole reliance on judicial review is insufficient to correct mistakes in the patenting process.

\section{A. How Do Incorrectly Issued Patents Survive in the Market?}

When the Patent Office grants an incorrectly issued patent, the patentee obtains property rights that generate a misallocation of resources, creating private and social costs. ${ }^{64}$ The existence of a "bad" patent, unless challenged successfully, creates a private cost: firms have to pay licensing fees in order to use the technology, and consumers have to pay higher prices to buy the patentee's products. A "bad" patent also creates a social cost, the sum of all the private costs plus the externalities over the investment processes of competing firms. ${ }^{65}$

The judicial system has traditionally prevented some incorrectly granted

58. See supra note 1 and accompanying text.

59. See generally Kesan, supra note 1; DiMatteo, supra note 27

60. See Reich, supra note 21(analyzing the boom of Internet and software related patents).

61. See generally Thomas, supra note 1 .

62. See Allison and Lemley, supra note 23 (evaluating the growing complexity of the patent claims presented at the Patent Office).

63. See Kesan, supra note 1; Allison and Lemley, supra note 23 (describing the complexity of new technology patents and the costly task of evaluating them).

64. See Kesan, supra note 1 , at 149-50.

65. The social costs of incorrectly issued patents include the following:

“(a) opportunistic licensing royalties/fees (including cross-licensing) collected from licensors who may rationally settle for a license instead of resorting to protracted litigation; (b) the disincentive to downstream innovation, i.e., the social cost of abandoned research activities by the patentee's competitors who may fear infringement; (c) the cost of wasteful designing-around activities by competitors; (d) the cost of rent-seekers, such as venture capital financers, who may choose to invest in start-up companies based on "bad" patents, thereby taking away resources from genuine entrepreneurs; (e) the social cost of supra-competitive pricing, in the absence of noninfringing product substitutes, based on "bad" patents; and (f) the filing and prosecution costs and the subsequent costs of having courts fix the Patent Office's oversight." Id. 
patents from surviving in the market. ${ }^{66}$ The judicial system provides competing firms and inventors with an avenue to evaluate and carefully circumscribe the patentee's rights over her invention. Litigation, however, is expensive. ${ }^{67}$ As we demonstrate in our model, the existence of high litigation costs allows many incorrectly granted patents to survive in the market.

Consider the following situation in which the Patent Office grants a "bad" patent. Figure 1 shows the different choices for the patentee and the alleged infringer/challenger. We begin with the assumption that the Patent Office granted a patent to firm $\mathrm{j}$, the patentee, and that a competitor, firm $i$, was particularly affected by this patent. Once the Patent Office granted the patent, firm i, has to decide between taking the case to the courts or letting firm $\mathrm{j}$ continue to have patent rights. In Figure 1, the first branches departing from firm i represent this choice. If firm i decides not to challenge the patent in court, then the patent will continue being valid and firm $i$ will have to pay a license fee to firm $j$ in order to use the patented invention (Result 1 in Figure 1). If firm i believes the patent is incorrectly issued, it can challenge the patent in court. At this point, firm $j$, the patentee, must act in order to avoid court action. Because litigation is expensive, a private agreement may often be a better solution for both firms. As a result, firm $\mathrm{j}$ has the opportunity to offer a private agreement to firm $i$ and stop the patent from going to court. If firm $\mathrm{j}$ decides not to offer a private agreement, the case goes to court, where the validity of the patent is decided.

In our model, we assume that the probability of a court ruling against a patent is represented by $\delta$, and (1- $\delta$ ) is the probability of the patent being declared valid (Result 2 in Figure 1). If firm $\mathrm{j}$ decides to offer a private agreement, then firm $\mathrm{i}$ has to evaluate the convenience of accepting such agreement. If firm i decides to accept the private agreement, then the patent will not be challenged in court, and both firms will decide the distribution of the payoffs (Result 3 in Figure 1). However, if firm i does not agree to bargaining for a private solution, the challenge will continue along its usual path through the courts (Result 4 in Figure 1).

66. However, as seen before, the chance of a patent being invalidated in court is close to $50 \%$.

67. See supra note 3 land accompanying text. 


\section{Figure 1}

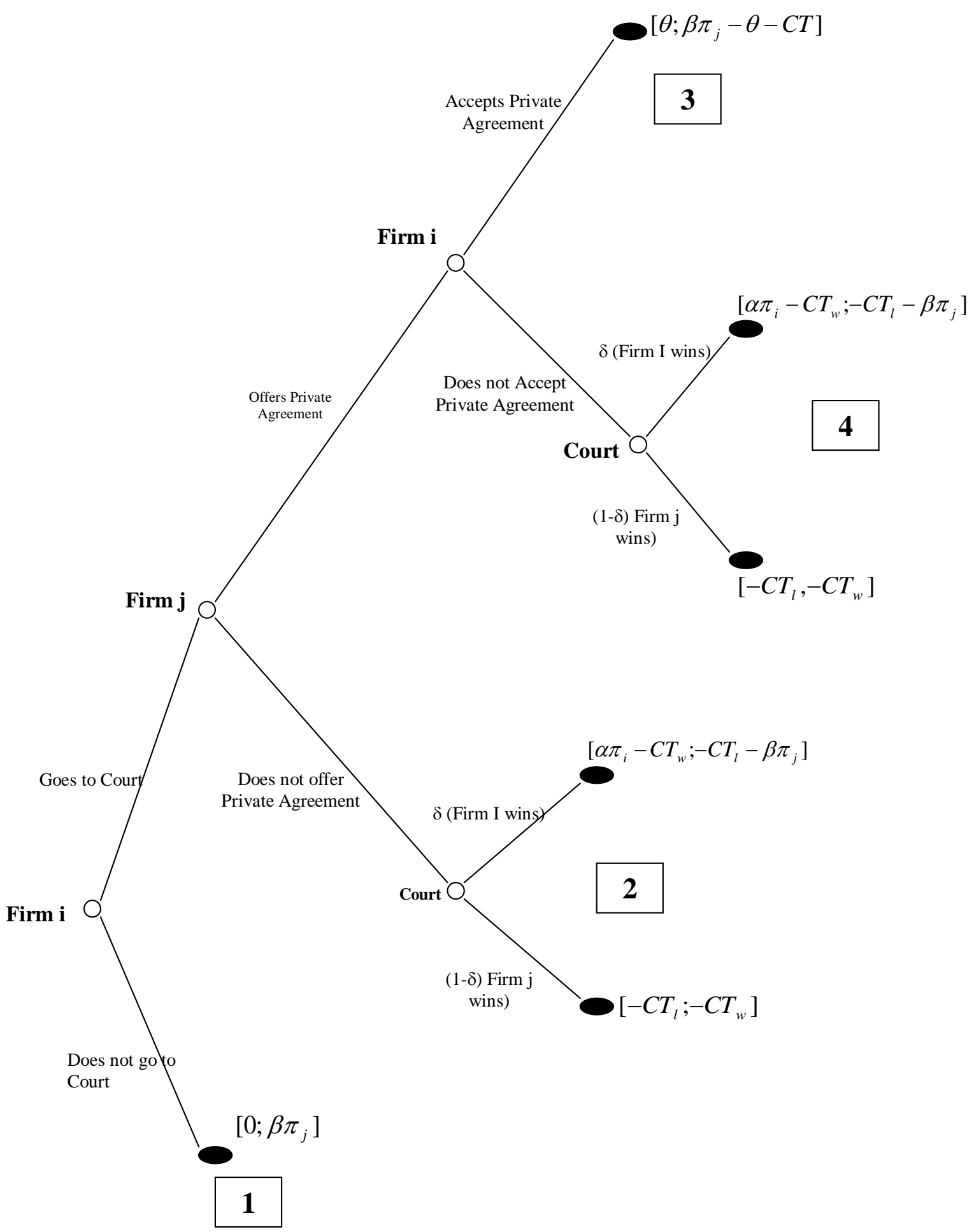


From our analysis we identify three different outcomes for a challenge of an incorrectly granted patent. First, the patent can survive without any challenge from competitors. This will happen when the benefit lost from the "bad" patent does not justify the costs of going to court; the challenger is better off leaving the patent in place than undertaking an expensive litigation process. Second, the patent can be challenged directly in court without any private agreement. This will happen when either firm i rejects a private offer from firm $\mathrm{j}$, or firm $\mathrm{j}$ never makes an offer to firm i. Finally, a private agreement among the parties will prevent the patent from being fully adjudicated in court. In this case, the "bad" patent survives but the challenger gets relief from the costs of the "bad" patent. "Bad" patents will only be challenged when the benefits lost by firm i, the challenger, are large enough to compensate for the high litigation costs and the patentee is not able to generate a private agreement to share some of the benefits and avoid or minimize litigation.

Based on the different equilibria in Figure 1, we can determine the best decisions for each player, depending on the size of the costs and benefits obtained, i.e., the net payoff in each different result. ${ }^{68}$ Following the model in Figure 1, let us assume the Patent Office grants a "bad" patent to a given firm (firm $\mathrm{j}$ ). As a result, a competitor (firm i), which was using the technology or process before the Patent Office granted the patent, has to decide how to protest such a mistake. If firm i decides to resort to court action, the expected payoff, from result 2 in Figure 1 , is the following:

$$
P=\delta\left(\alpha \pi_{i}-C T_{w}^{i}\right)-(1-\delta)\left(C T_{l}^{i}\right)
$$

Where:

$\delta$ is the probability of winning the trial;

$\mathrm{CT}_{\mathrm{w}}{ }^{\mathrm{i}}$ is the cost of resorting to a court, given that the firm wins the trial;

$\mathrm{CT}_{1}^{\mathrm{i}}$ is the cost for the challenger if the court favors the patentee;

$\alpha \pi_{\mathrm{i}}$ is the fraction of the firm profits gained if the patent is invalidated, or equivalently, the fraction of the profits lost because of the existence of the new patent; and we assume $\alpha<1$.

Equation (1) tells us that firm i's expected payoff in going to a court is equal to the benefit expected if a court favors its claim (the firm's lost profits minus the total costs of going to trial) minus the expected cost if the court decision favors the patentee (the costs of going to trial and losing the challenge). The expected payoff can be either positive or negative. This depends not only on the size of litigation costs, but also on the probability of success in court.

If the firm decides not to go to trial, the patent would stay in effect; i.e., the firm would either have to pay licensing fees for using the technology or change its investment process in order to avoid using the patent (Result 1 in Figure 1). Accordingly, the payoff would be:

$P=0$

68. See Appendix A for more details on the algebra of the model. 
If firm i decides not to resort to litigation, then the payoff is represented by the lost benefits due to the existence of the new patent. After accounting for equations (1) and (2), this firm will decide to go to court when the expected payoff from going to trial is greater or equal to the payoff received by allowing the patentee to exploit its monopoly. Using equations (1) and (2) and simplifying, we obtain the following inequality:

$(1+\delta) \alpha \pi_{i} \geq \delta C T_{w}^{i}+(1-\delta) C T_{l}^{i} \quad$ (Goes to Court)

$(1+\delta) \alpha \pi_{i} \leq \delta C T_{w}^{i}+(1-\delta) C T_{l}^{i} \quad$ (Does not go to Court)

In the first case, when the expected benefits from contesting the patent are greater than the expected costs of resorting to litigation, firm will i prefer to take the case to court. In the second case, when the benefits are too small as compared to the expected costs, firm $\mathrm{i}$ will prefer to pay licensing fees or change its investment process in order to avoid illegal use of the newly patented technology. In this latter case, the incorrectly issued patent produces an inefficient economic result. Consequently, the high transaction costs created by expensive courts and the patent process permit "bad" patents to survive. Now, assume that according to equation (3) the optimal decision for firm $i$ is to let a court decide the patent dispute; i.e., the expected benefits are greater than the expected costs. Even in this case, the patentee can still prevent this challenging firm from going to court and allow the patent to survive. For the patentee to be able to reach this goal, he or she has to offer firm i a fixed compensation, called $\theta$, such that:

$\left.(1+\delta) \alpha \pi_{i}-\theta \leq \delta C T_{w}^{i}\right)+(1-\delta) C T_{l}^{i}$

As a result, the patentee is paying firm i a share of its benefits in order to induce firm $i$ to change its choice and refrain from going or continuing its action in court. This compensation, $\theta$, is not necessarily a money payment to the challenging firm. Rather, the payment is similar to any licensing or settlement arrangement between the patentee and the challenging firm involving patent rights. For example, the parties could agree on low licensing fees for the use of the patented technology or for sharing specific rights. This agreement increases the cost of going to court by changing the inequality sign in equation (3) in such a way that now the optimal behavior for firm $\mathrm{i}$ is to not go to court; rather, the optimal behavior now is to accept a private agreement. Hence, in some cases, firm $\mathrm{j}$ can generate a payoff for firm $\mathrm{i}$ in order to change the optimal result from going to court to a private agreement. Solving equation (4) results in obtaining the minimum value for the payment needed to avoid court intervention:

$\theta \geq(1+\delta) \alpha \pi_{i}-\delta C T_{w}^{i}-(1-\delta) C T_{l}^{i}$

For the patentee, the payoffs of going or not going to court are:

$P=\beta \pi_{j} \quad$ (Patent is not contested in Court)

$P=(1-\delta)\left(-C T_{w}^{j}\right)-\delta\left(C T_{l}^{j}+\beta \pi_{j}\right) \quad$ (Patent is contested by firm i) 
Where:

$\beta \pi_{\mathrm{j}}$ is the monopoly profits received by the firm from the patent;

$(1-\delta)$ is the probability of winning the trial;

$\mathrm{CT}_{\mathrm{w}}{ }^{\mathrm{j}}$ are the court costs when the patentee wins the trial; and

$\mathrm{CT}_{1}^{\mathrm{j}}$ are the court costs when the patentee loses the trial.

This equation suggests that if the patent is not contested, firm $j$ will receive the increase in its profits produced by the newly granted patent. If, however, the patent's validity is evaluated by a court, the expected payoff will be the patent benefits minus the costs of going to court and winning the suit, minus the benefits from the patent plus the costs of going to court and losing the trial. As a result, firm $\mathrm{j}$ will be willing to pay to firm $\mathrm{i}$ the amount $\theta$, so long as: ${ }^{69}$

$$
(1+\delta) \beta \pi_{j}+(1-\delta) C T_{w}^{j}+\delta C T_{l}^{j} \geq \theta+T C
$$

TC represents the transaction costs of reaching an out-of-court solution by the parties. Equation (7) shows that firm $\mathrm{j}$ will be able to pay $\theta$ as long as this compensation plus the private transaction costs (TC) are less than or equal to the difference between the expected payoff of not going and going to court. If $\theta+\mathrm{TC}$ is greater than this difference, then it is optimal for firm $\mathrm{j}$ to allow firm $\mathrm{i}$ to resort to litigation; the expected payoff would be greater than the net profit after paying the private compensation.

By inserting equation (5) into equation (7), and assuming the court costs are the same for both parties, we obtain:

$(1+\delta)\left(\beta \pi_{j}-\alpha \pi_{i}\right)+\left(C T_{w}+C T_{l}-T C\right) \geq 0$

Accordingly, equation (8) suggests that firm $\mathrm{j}$ will be able to offer the side payment $\theta$ to firm $\mathrm{i}$ as long as the patent profit for firm $\mathrm{j}$ is larger than the patent losse for firm i. Also, the costs of going to court must be greater than the transaction costs of reaching a private agreement. Solving for $\pi_{\mathrm{j}}$ :

$\pi_{j} \geq \frac{\alpha}{\beta} \pi_{i}-\frac{\left(C T_{w}+C T_{l}-T C\right)}{(1+\delta) \beta}$

In order to visualize how costs and benefits determine these different results, we have graphed the reaction curves for the patentee and the challenger. Figure 2 shows the relationship between the profits of both firms and defines the different incentives for the participants. The horizontal axis represents the level of profit for firm i $\left(\pi_{\mathrm{i}}\right)$, which increases to the right. The vertical axis represents the patentee's profit $\left(\pi_{\mathrm{j}}\right)$, which increases to the north. The vertical line represents equation (3),

69. See Appendix A for an algebraic derivation of this formula. 
showing the minimum level of profit firm i needs in order to be profitable when resorting to court action. ${ }^{70}$ Accordingly, to the left of this line is the optimum value for firm i not to resort to judicial action and let the "bad" patent to survive without challenge. Meanwhile, to the right of this line it is optimal to resort to judicial review of the patent. For the patentee, the positive sloping curve represents equation (9). In the area below the curve, it is optimal for the patentee to not offer some compensation $\theta$ to firm $i$ in order to avoid court action. Above this line, however, it is optimal to offer such compensation in order to reach a private agreement. Therefore, we have four well-defined areas in this figure. In area I, the patentee cannot offer compensation to firm i, but it is also not optimal for firm i to go to the court. As a result, the patent is not challenged and simply survives in the market as a "paper patent." In area II, the patentee is able to offer some agreement or compensation to firm i, but the optimal strategy for firm $i$ is to not resort to the judicial system. Consequently, the patentee retains her rights without any challenge. In area III, the patentee can achieve a private agreement in order to avoid potentially adverse court decisions. For firm i, it may be economically advantageous to let a court decide the validity of the patent. But in area III, it is optimal for both parties to reach a private agreement in which the patentee convinces firm i to not go to court or continue to maintain any action in court. Finally, in region IV, the patentee is not able to offer an agreement satisfactory to firm i, and it is optimal for firm i to go to court. Hence, in this region we should expect claims to be filed in court and the patentee's rights to be legally challenged.

Our analysis suggests that judicial action is likely in just one of the four possible areas. In the three other areas, we observe that incorrectly issued patents produce inefficient results in the economy. As a consequence, costs of litigation create an environment in which incorrectly issued patents survive in the market. This problem produces private costs for the firms that have to pay for patents and social costs that have an aggregate effect on the economy.

In order to approximate our results to real life situations, assume that the profits for both firm $\mathrm{i}$ and $\mathrm{j}$ should always be positive, i.e., they need positive profits in order to participate in the market. Figure 3 shows the possible outcomes of an incorrectly issued patent. Region I of Figure 2 is not a possible outcome because the profit of the patentee is negative. ${ }^{71}$ Accordingly, firm $j \mathrm{can}$ always provide compensation in order to avoid litigation when the profits of firm $i$ are low enough to make a private agreement possible. Nonetheless, if firm i's loss is large enough, then an offer of compensation is not possible, and the case will end up in court.

Our model produces three possible outcomes. First, the "bad" patent survives because it is not economical for firm $i$ to go to court (Region II). In this situation, the patent stays effective and the patentee earns profits from licensing or selling products. The patentee would also be able to enter into a private agreement with the challenger, but it is not economical given the disincentive for firm $i$ to litigate. Second, firm $\mathrm{i}$ is willing to go to court. Firm $\mathrm{j}$ can, however, create a private arrangement so firm i does not continue action in court (Region III). In this situation, the "bad" patent survives in the market, but the private agreement lowers firm i's costs. In the final situation, firm i's optimal behavior is to go to court and firm $\mathrm{j}$ cannot pay the required amount to avoid this court challenge (Region IV).

70. See Appendix A for a graphical and algebraic derivation of Figure 2.

71. See Appendix A for a mathematical derivation of Figure 3. 


\section{FIGURE 3 (top) and FIGURE 2 (bottom)}

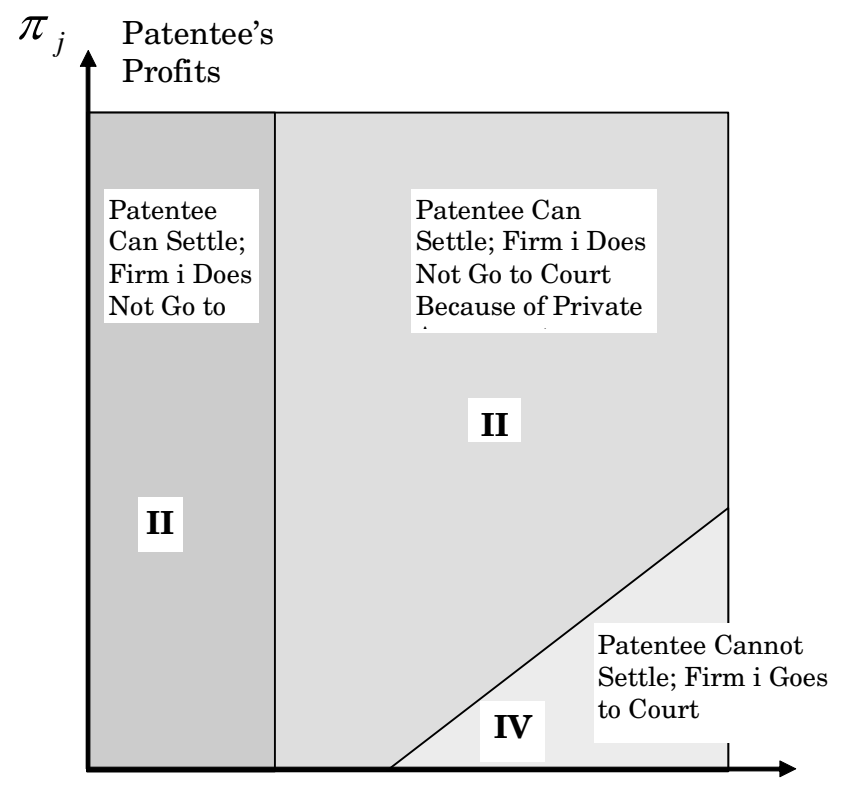

Challenger/Alleged Infringer' s Profits

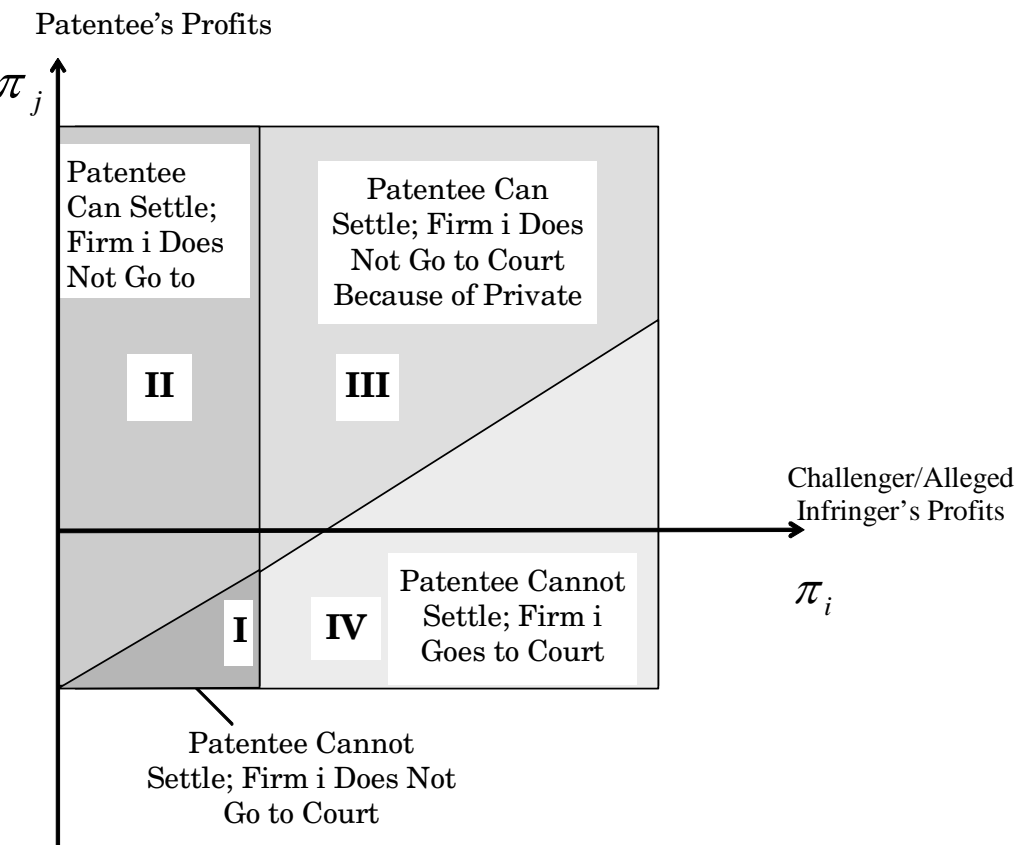




\section{B. Changes in Litigation Costs}

Litigation costs have an important role in determining the chances of a patent going to court. ${ }^{72}$ The high transaction costs required to revoke "bad" patents decrease social welfare. ${ }^{73}$ In many cases, patents are not challenged at all because the challenger's litigation costs are prohibitively high. ${ }^{74}$ A party challenging a patent risks losing a high level of profits. ${ }^{75}$ Litigation costs are not limited to the direct costs of using the court, but also include indirect costs derived from externalities of litigation costs, the existence of temporary "bad" patents, and opportunity costs of challengers. "76 Accordingly, the granting of "bad" or unnecessary patents by the Patent Office generates significant costs for the firms and consumers that want to challenge the patent grant. ${ }^{77}$

In this section, we address the question of how changes in litigation costs affect the firms' incentives to resort to the courts. ${ }^{78}$ The manner in which changes in litigation costs affect the expected payoff is depicted in Figure 1. Figure 4 shows the effect of increasing litigation costs, $\mathrm{CT}_{\mathrm{w}}$ and $\mathrm{CT}_{1}{ }^{79}$

The increase in litigation costs will move both the $\pi_{\mathrm{i}}$ and $\pi_{\mathrm{j}}$ profit lines to the right. The effect of such movement is an increase in the area of region II and a decrease in the area of region IV. ${ }^{80}$ The effect on region III is not apparent. On the one hand, the increase in litigation costs will change the expected payoff for firm $i$ of going to court to contest the incorrectly issued patent held by firm $j$. Firm i will need a higher minimum profit loss to choose court action. Because of the higher litigation costs, we should expect more "bad" patents to survive without

72. See infra Part II.

73. See generally Kesan, supra note 1.

74. "[T]he high costs of patent litigation may discourage other retailers from challenging a patent at all. As a result, competitors of the patentee may be discouraged from engaging in the patented method. Consumers who wish to take advantage of the patented business features must then transact with the patentee." Thomas, supra note 1 , at 320 .

"Firms with high litigation costs appear less likely to patent in the same subclass as rivals. These firms seem particularly reluctant to patent after awards to firms that have low litigation costs." Josh Lerner, Patenting in the Shadow of Competition, 38 J.L. \& ECON. 463, 489-90 (1995).

75. See supra note 31 and accompanying text.

76. See Crane, supra note 31 (describing the characteristics of direct and indirect litigation costs for patent cases).

77. "The grant of unneeded patents generates substantial costs, especially as far as they can be used to block or delay innovation by third parties, or the introduction of competitive products at lower prices. Under most patent laws, the refusal to grant a license is not an antitrust offense or a straightforward ground for the granting of a compulsory license. Hence, the only option available to the public and competitors is to challenge the validity of the patent, generally a difficult and costly task beyond the reach of small and medium enterprises. In the USA, for instance, the costs of a typical infringement suit are estimated to run to $\$ 1-3$ million; moreover, litigation is a lengthy process (one estimate suggests that the duration of the "average" patent suit in District Court is 31 months), meaning that potential infringers are either paying royalties or risking costly infringement penalties for long periods until a final decision on the patent is reached." Correa, supra note 10 , at 543 .

78. We are not evaluating court performance in this paper, but providing an analysis of how lower costs can change the willingness to use the court system to challenge patents. See Kimberley A. Moore, Judges, Juries, and Patent Cases. An Empirical Peek Inside The Black Box, 11 Fed. Circuit B. J. 209 (2001-2002) (studying empirically how courts manage different patent cases).

79. See Appendix A for the mathematical expression for derivatives and pictures. Here we represent the effects of a change in $\mathrm{CT}_{1}$, i.e. the cost when any of the parties lose the trial. However, the analysis of changes in $\mathrm{CT}_{\mathrm{w}}$ are straightforward.

80. See Appendix A Equation (14) and Figure 2A. 
being challenged. On the other hand, it is now more expensive for firm $\mathrm{j}$ to let firm $i$ to go to court. In this case, it would be more desirable to offer private compensation to stop the judicial process. As a result, the movement of the curve $\pi_{\mathrm{j}}$ to the right increases the area of region III; i.e., some patents that previously were part of a private agreement are now surviving without challenge. Region IV will shrink as going to court becomes more costly for both parties.

For region III, there are two effects that produce a mixed result (Figure 5). First, more patents are bargained for privately before going to court; this increases Region III (Area B in Figure 5). Second, "bad" patents that previously could be contested and bargained for privately are now not contested because of the potential court costs (Area A in Figure 5); this reduces area III. The net effect of an increase in litigation costs for Region III is uncertain.

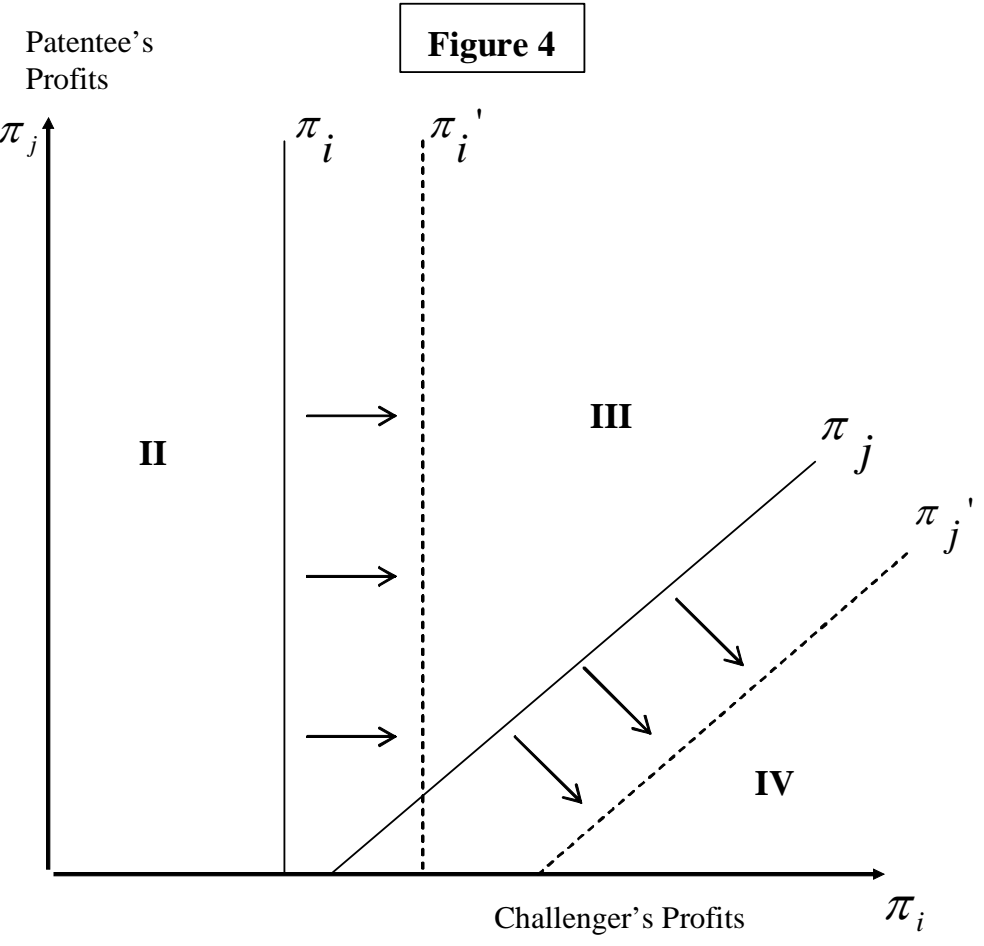




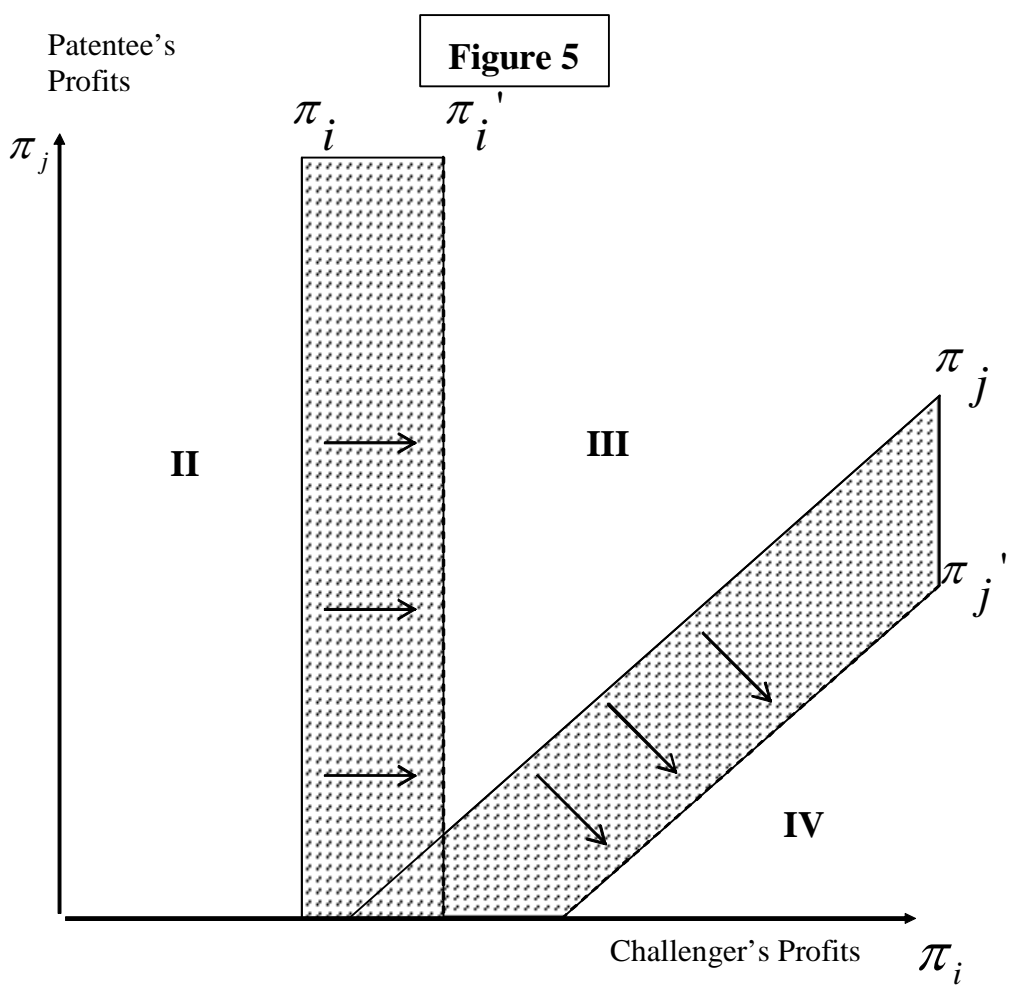

Evaluating the total effect of litigation costs on the decision of taking a "bad" patent to court suggests that more "bad" patents survive in the market because of increased court costs. Corresponding to the increase in litigation costs, Region II and Region III areas also increase with respect to Region IV, which decreases. This means that more total patents are prevented from being reversed by a court (Figure 5). Furthermore, firms that patent in an aggressive fashion will benefit from these high court costs.

\section{Court Performance}

The current patent system relies on the judicial system to solve the problem of incorrectly issued patents. ${ }^{81}$ Courts, however, are not necessarily well-informed or well-qualified to evaluate the validity of issued patents. ${ }^{82}$ In recent years, the increase of patents on Internet business methods and software technology has opened new areas of patenting in which judges have almost no experience. ${ }^{83}$ As a

81. See infra Part III.

82. See infra Part I.

83. "He [Judge Friendly] noted, 'courts must deal today with a great number of patents in the higher reaches of electronics, chemistry, biochemistry, pharmacology, optics, harmonics, and nuclear physics, which are quite beyond the ability of the usual judge to understand without the expenditure of an inordinate amount of educational effort by counsel and of attempted self-education by the judge, and in many instances, even with it."' LeRoy L. Kondo, Untangling The Tangled Web: Federal Court Reform Through Specialization For Internet Law And Other High Technology Cases, 2002 UCLA J. L. \& TECH. 1, 1 (2002).

"Also, because courts then (and now) are not necessarily well trained in technology issues, the risk of error at trial was significant. Hence, there was even more expense, in the form of appeals to have an erroneous trial 
consequence, courts do not always eliminate "bad" patents. Rather, "bad" patents can survive, even after review by a court. In our model we assume that the probability of successfully invalidating a "bad" patent in court $(\delta)$ is fixed. $^{84}$

In this section, we evaluate the effect of an improvement in court performance by increasing the probability of rejecting a "bad" patent. Figure 6 shows the effect of an increase in probability of court assessment of "bad" patents. ${ }^{85}$ The improvement in court performance produces a shift to the left for both curves, $\pi_{\mathrm{i}}$ and $\pi_{\mathrm{j}}$. As the court is more efficient, firm i's expected payoff from resorting to court to challenge the patent will improve. Many "bad" patents that previously were left uncontested are now going to court (increase in Region II area). For firm $\mathrm{j}$, paying private compensation in order to avoid court action is now more expensive given that court success is more probable for firm i (decrease in area III). As a result, we observe that area IV increases; i.e., now more "bad" patents are being contested in court. Region II decreases as the probability of success in going to court increases, thus increasing the payoff for firm $i$. Nonetheless, the effect of better court efficiency on area III is uncertain. Some patents that previously were bargained for privately now are going to court, decreasing the area of Region III. Patents that were not taken to court, however, are now being contested and firm $\mathrm{j}$ will have to provide a private solution in order to avoid court. Consequently, the effect of better court performance has a mixed effect on the area of region III.

The total effect of an improvement in court performance is clearly unfavorable for "bad" patent holders. If the judicial system improves the chances of rejecting a "bad" patent, the expected payoff from having a "bad" patent will decline. This decrease will improve the expected payoff for those who are thinking of going to court to contest the "bad" patent. From our previous discussion and other studies about court performance and "bad" patents, we observe a tendency of the system to worsen when dealing with "bad" patents.

result reversed. Because of the cost and the potential for error, the threat value of even an invalid patent was substantial." Merges, supra note 1, at 595.

84. See Moore, supra note 78 (providing statistical analysis of the probability of winning a trial in court for both the patentee and the challenger).

85. See Appendix A for the mathematical analysis of derivatives and a picture. 


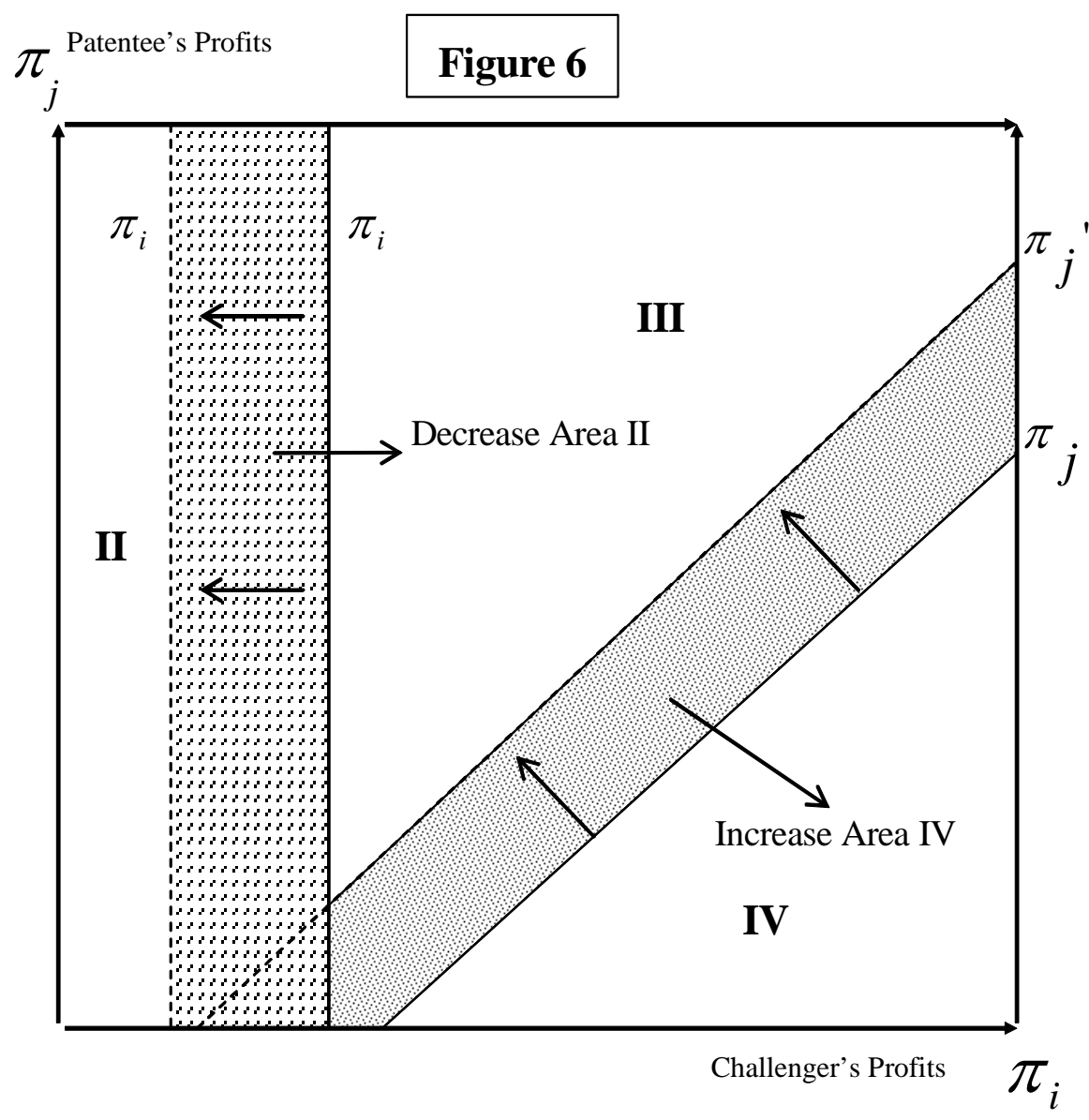

\section{Private Transaction Costs}

In this section we analyze the effect of a change in the costs of agreeing privately without going to court. This cost is important for the patentee, because it can determine the probability of making such a private payoff and avoiding court intervention. In real life situations, most patent disputes are solved by some kind of agreement between the parties. ${ }^{86}$ In some cases, it is also better for the challenger to have low private transaction costs that permit reaching a private agreement instead of the uncertainty of court. Figure 7 illustrates the effect of an increase in this private transaction cost. ${ }^{87}$ This cost is paid by firm $j$, which is more interested in compensating the challenger privately, thus avoiding court

86. "Surprisingly, few patent cases go to trial each year. For the period of the study, the percentage of patent suits going to trial each year ranged from $3.3 \%$ to $11.9 \%$. The percentage of suits going to trial for the entire period was $6.9 \%$."

"The vast majority of suits are resolved in advance of trial either by the court on dispositive motion or by the parties themselves through settlement." Moore, supra note 78, at 230-31.

87. See Appendix A for the mathematical analysis of derivatives and picture. 
action and the possibility of patent revocation. An increase in the transaction costs of reaching a private agreement will move the reaction curve for firm $\mathrm{j}$ to the right, leaving the curve for firm $\mathrm{i}$ unaltered. In this new situation, firm $\mathrm{j}$ will not be able to pay the required private compensation for some levels of profit. As a result, some "bad" patents, which were previously subject to private agreements, are now challenged in court. This increase in private transaction costs leads to more litigation, which is not necessarily desirable for firm i. Even though going to court is more expensive than a private agreement, in this case, a private payoff is preferred.

From our model, we conclude that higher private transaction costs reduce the expected payoffs for both firms. This is because some patent disputes previously solved privately are now going to court, where costs are higher. Furthermore, because a patent can survive a court challenge, court intervention does not indicate that the problem is decisively solved.

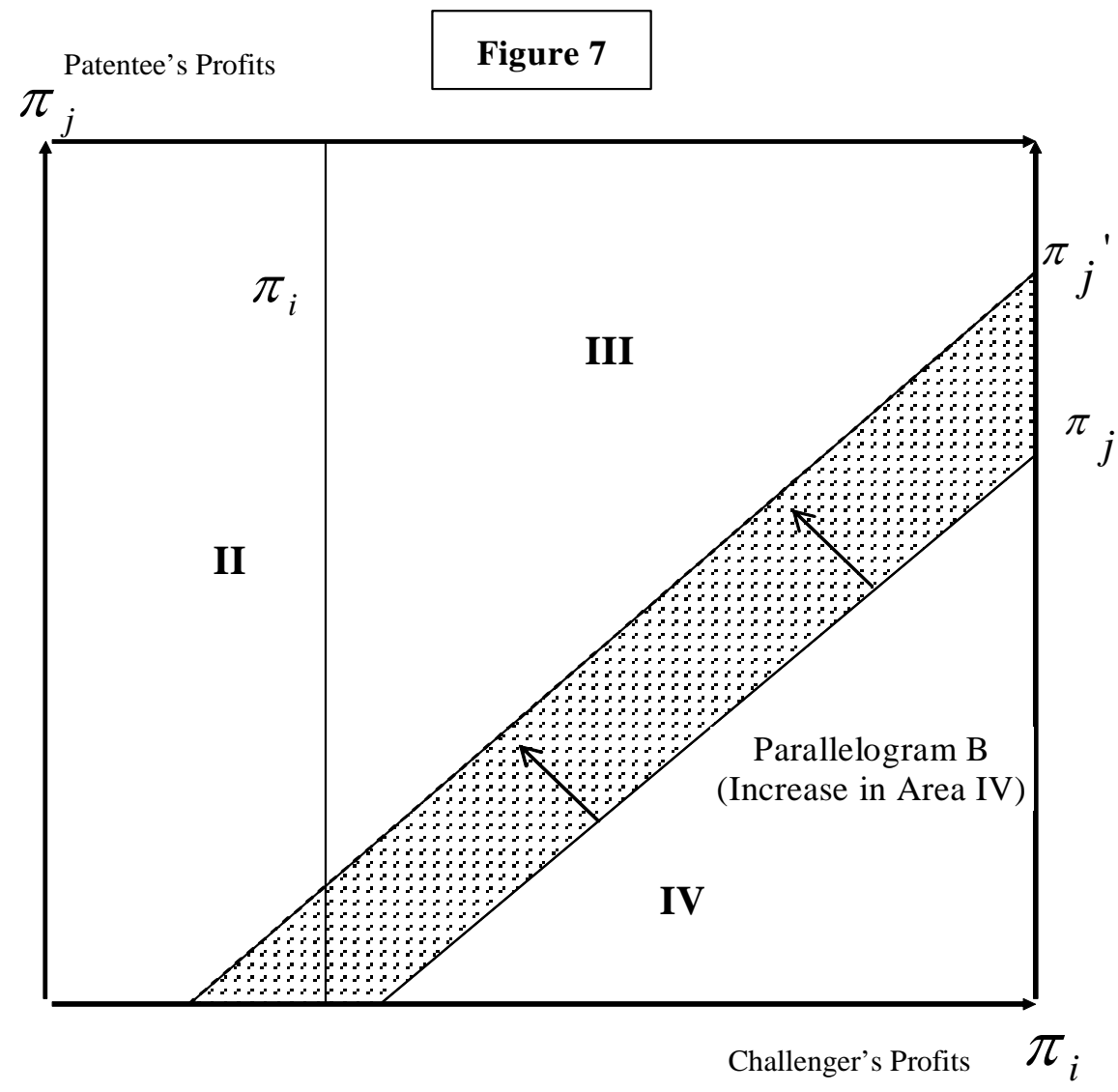




\section{REFORMING THE PATENT OFFICE}

In the previous sections we analyzed how the system for challenging incorrectly issued patents works in the U.S. We also demonstrated how the lack of a thorough review of claims by the Patent Office, coupled with the high cost and uncertainty of the court system produces a large number of "bad" patents that survive in the market. In this section, we adjust our model to introduce changes to this patent regime in order to reduce the number of "bad" patents.

In recent years, the performance problems of the Patent Office we described in previous sections prompted many scholars and commentators to propose new regimes for granting and managing patents. ${ }^{88}$ Many of these proposals included the creation of an opposition system inside the Patent Office. ${ }^{89}$ Such a system has proven in the European and Japanese regimes to be a useful instrument for reviewing patents. ${ }^{90}$ In order to analyze the effectiveness of such an opposition system in the U.S. patent regime, we modified our model by permitting challenges to a patent at the Patent Office. ${ }^{91}$ As a result, once a patent is granted, or just before it is granted, ${ }^{92}$ there is a limited period of time during which firms or individuals can challenge a patent's validity. ${ }^{93}$ The Patent Office will subsequently review its own decision concerning the challenged patent or business method. ${ }^{94}$ If the patent is not challenged after the legal period, further claims must be brought in court. ${ }^{95}$ Even if the Patent Office declares a challenged patent valid, the firm or individual pursuing the challenge can decide to continue in court. We assume, however, that once the Patent Office reviews a patent and validates it, the information generated and the decision made will improve the chances for a court to make a more informed decision. As a result, we assume that the Patent Office's challenge system will be complementary to the court system, rather than merely a substitute.

Based on our previous model described in Figure 1, Figure 8 illustrates the new regime for an opposition system for patents granted by the Patent Office. In this new model, firm $i$, the challenger, can resort to the opposition system of the Patent Office to challenge firm j's patent. This is represented by the first choice firm i has in Figure 8, when the challenger has to make a decision of whether to challenge firm j's patent or not. If firm i decides not to challenge the new patent, then the patent continues to be valid and firm $i$ has to pay licenses and other fees to firm $\mathrm{j}$ (Result 1, Figure 8). If firm $\mathrm{i}$ decides to challenge the validity of the patent using the Patent Office opposition system, then firm $\mathrm{j}$ can decide to offer or not to offer a private agreement to firm i that may stop the opposition proceedings. We assume that the parties are free to reach a private agreement in order to avoid any

\footnotetext{
88. See supra note 1 and accompanying text for citations on proposals about change in the Patent Office system.

89. See e.g., Merges, supra note 1; Kesan, supra note 1; Thomas, supra note 1.

90. See Kesan, supra note 1 , at 158 .

91. Our model can be used to explain post-grant or pre-grant opposition systems, since the difference in results would be the impact of each regime on the costs of using any of these regimes and the incentives the Patent Office faces in each alternative. Kesan, supra note 1, at 158-65 (describing the advantages and disadvantages of each system).

92. See discussion on the types of opposition systems infra Part IV.3.

93. See Kesan, supra note 1, at 158-65 (describing the advantages of having a limited time for oppositions). See also infra Part V.

94. See discussion on the types of review panels and the incentives of the Patent Office infra Part IV.3.

95. See discussion on the scope of estoppel infra Part IV.4.
} 
review. If firm $\mathrm{j}$ does not offer a private agreement, then the Patent Office opposition system decides the validity of the patent. We assume that the Patent Office will revoke the patent with probability $\gamma$ and will validate it with probability $(1-\gamma)$. If the Patent Office validates the patent, firm i can challenge the patent in court. $^{96}$ The fact that the Patent Office has already reviewed the patent will give the court more information in order to decide the case. If firm i decides not to go to court, then the patent is validated (Result 2 in Figure 8). But if firm i goes to court, then the patent will be rejected with probability $\delta$ and accepted with probability (1- $\delta$ ) (Result 3 in Figure 8).

In the case that firm $\mathrm{j}$ is willing to offer a private agreement, the options for firm $i$ are to accept the agreement or to let the Patent Office decide the case. If firm i decides to agree privately, then the case is solved without challenging the patent; the patent can survive even if invalid (Result 6 in Figure 8). But if firm i rejects the agreement, the Patent Office has to take the case and decide on the validity of the patent. As before, if the Patent Office declares the patent valid, firm i can decide to go to court (Result 5 in Figure 8) or accept the Patent Office's ruling (Result 4 in Figure 8). Otherwise, the Patent Office revokes the patent and firm $\mathrm{j}$ has to renounce any rights over it.

As a result, we have five possible equilibria for this model. First, firm i does not challenge the patent, it is declared valid, and the "bad" patent will survive. Second, firm i uses the opposition system and the Patent Office revokes the patent. This alternative is less expensive than court and provides a useful instrument to review the Patent Office granting procedure. Third, firm i decides to use the opposition system but firm $\mathrm{j}$ offers a private agreement protecting the patent. In this case, the chance of producing a private agreement still exists, however, it would be more difficult for the patentee to convince the challenger to enter into a private agreement, given the lower cost of resorting to the opposition system for review compared to the cost of litigation. As a consequence, the existence of a challenge procedure less expensive than court could lessen the negative effects of the "bad" patents, even in cases involving private agreements. Fourth, firm i decides to use the opposition system, the Patent Office declared the patent valid, and firm $i$ does not challenge this decision in court. Finally, firm i uses the opposition system, the Patent Office declares the patent valid, but firm i decides to take the case to court. In this situation, the challenger has a second opportunity for review in court.

96. The capacity of the challenger to continue with a court procedure will depend on the scope of the estoppel and actions available to the opposition panel. See infra Part IV.4 for a discussion on the scope and nature of the estoppel. 


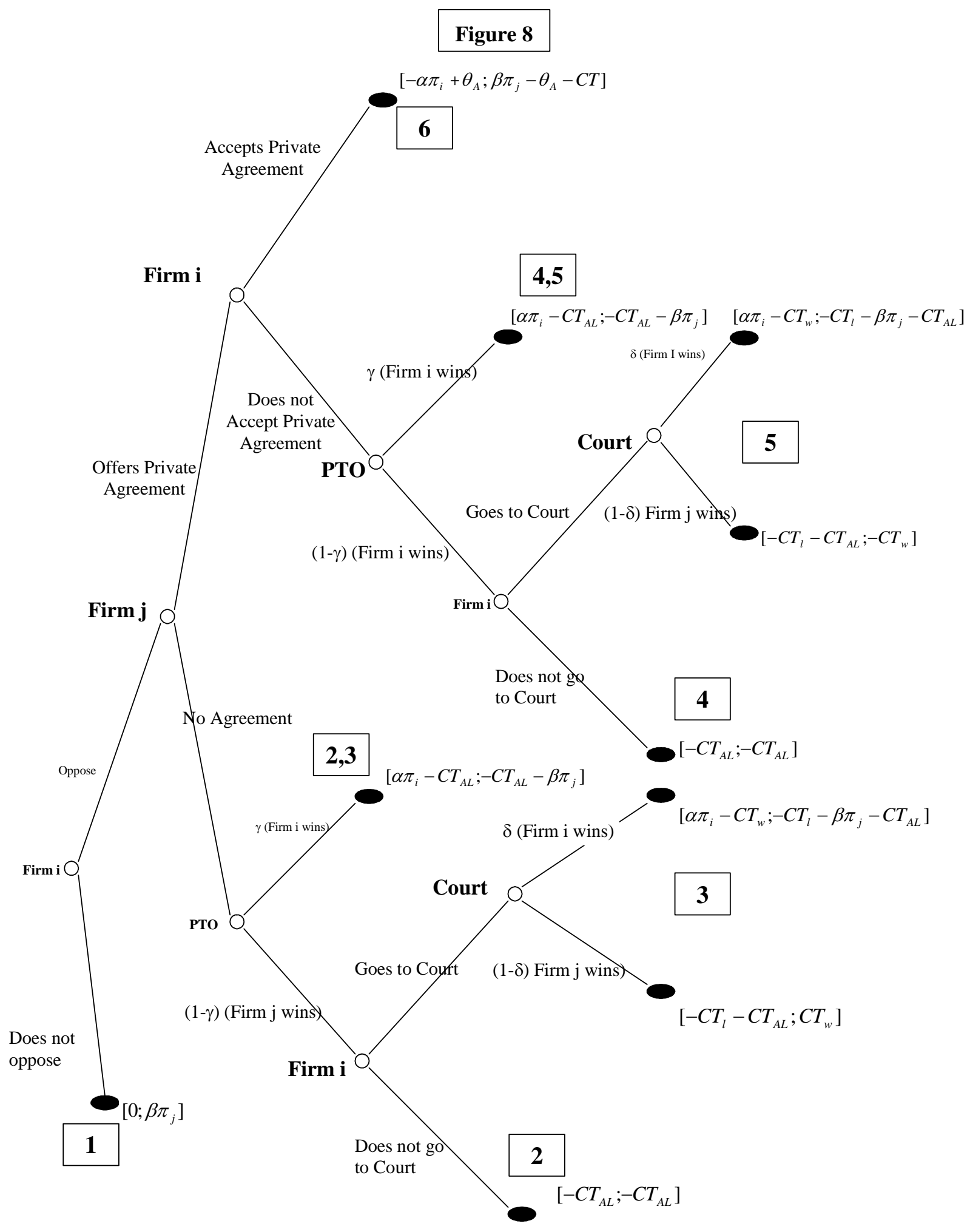




\section{A. The Model}

Given the model described in the previous section, in this section we analyze the payoffs generated by the different equilibria. From the new opposition system managed by the Patent Office and described in Figure 8, the expected payoffs for firm $\mathrm{i}$ and firm $\mathrm{j}$, for each possible result, are listed below. ${ }^{97}$

Result 1: Firm i does not challenge the validity of the patent. Accordingly, firm i will have to pay licensing fees to the patentee in order to use the technology, while firm $\mathrm{j}$ will enjoy the benefits of the patented technology.

Result 2: Firm i decides to challenge the validity of the patent, there is no private agreement between firm $j$ and firm $i$, and firm i does not go to court. In this case, the expected payoff for each firm is the expected value from the Patent Office decision with respect to the validity of the patent.

Result 3: Firm i challenges the patent, there is no private agreement, but firm i decides to go to court in case it loses the challenge within the Patent Office. In this case, the expected payoff for each firm $\mathrm{i}$ is represented by the probability of win ning the case in the Patent Office or through litigation, if the Patent Office does not grant a favorable verdict. For firm $\mathrm{j}$, the expected payoff is represented by the probability of receiving a favorable verdict by the Patent Office or court. We assume that in the event of winning in court, the cost of using the Patent Office is refunded to the winning party. In another alternative, not explored in this paper, this cost, or a fraction thereof, could be charged to the Patent Office as a disincentive/penalty for producing wholly non-persuasive decisions. The differences resulting from the treatment of this cost do not affect the main results.

Result 4: Firm $i$ challenges the patent, firm $j$ offers a private agreement, and firm i does not go to court after having lost the opposition. In this case, the payoff will be determined by the comparison of the expected payoff from the private agreement and the Patent Office decision. Because there is no court intervention, the procedure will stop after the Patent Office's decision is rendered.

Result 5: Firm $i$ challenges the patent, firm $j$ offers a private agreement, and firm i goes to court after having lost in the Patent Office. This case is similar to the last one, but now the challenger is willing to take the case to the court in the event it receives an unfavorable verdict from the Patent Office.

Given the expected payoffs in each situation, we should analyze the different strategies of the players with respect to the different courses of action. First, firm i must initially decide if it is optimal to resort to an opposition or not, and then to go to court or not. For the decision of whether or not to challenge the patent with an opposition, firm i must compare the expected payoff of result 1 with the expected payoff of result 2. Comparing the expected payoff in 1 with respect to 2 , we obtain. $^{98}$

$\pi_{i}=\frac{C T_{A L}}{\alpha \gamma}$

97. For a formal derivation of this model see Appendix B.

98. See Equation 6, Appendix B. 
If the total benefit is greater than the right hand side of equation (10), firm $\mathrm{i}$ will prefer to resort to the opposition system of the Patent Office. Otherwise, firm i will not challenge the patent, and the optimal strategy will be to pay for the use of the technology or method.

By comparing the expected payoff in result 2, where firm i resorts to an opposition but does not go to court, with the expected payoff in result 3 , when firm i will go to court, we find: ${ }^{99}$

$\pi_{i}=\frac{-\delta C T_{A L}+\delta C T_{w}+(1-\delta) C T_{l}}{\delta \alpha}$

In this case, if the benefit to firm $i$ is greater than the right hand side of equation (11), then firm i will prefer to go to court after having lost the opposition in the Patent Office. ${ }^{100}$ Otherwise, it will prefer to not go to court. Observe that the minimum level of benefit required to make the court an optimal solution increases with the probability of winning the opposition and any subsequent court trial.

From our assumptions, the minimum level from equation (11) is greater than that of equation (10). Figure 9 shows the areas of decision for firm i. There are three different decision regions. In the first region, firm i's best decision is to not challenge the patent. In the second region, the optimal strategy is to let the Patent Office decide the validity of the patent without going to court. Finally, in the third area, the patent is challenged under both the Patent Office and the court system. As we can see, whether the patent is challenged will depend on the amount of profits firm i loses by the existence of the patent and the cost of resorting to the opposition system and the courts.

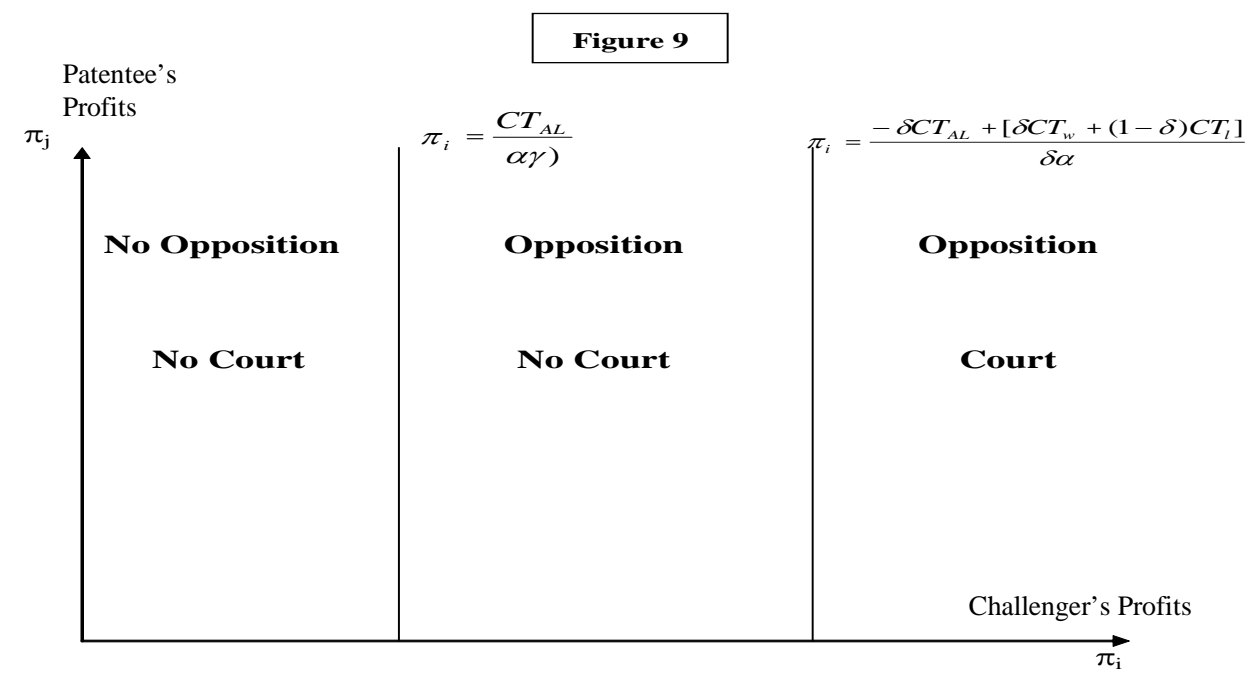

99. See Equation 7, Appendix B

100. If we compare the expected result of not going to court, result 4, with the expected payoff of going 
Firm $\mathrm{j}$ should evaluate the costs and benefits of whether or not to offer a private agreement to firm i. Accordingly, we should compare the expected payoffs from situations 2 and 4, in which firm i does not go to court, and situations 3 and 5, in which firm i's optimal strategy is to resort to the courts. From this comparison, we can derive two different sets of equilibria for firms $j$ and $i$. In the first equilibrium, the reaction function separates the regions in which firm $j$ will or will not offer a private agreement. Firm i will not go to court after an unfavorable verdict from the Patent Office. The following equation describes such a reaction function. ${ }^{101}$

$\pi_{j}=\frac{\alpha \gamma \pi_{j}+T C-2 C T_{A L}}{(1+\gamma) \beta}$

When the total profit for firm $\mathrm{j}$ is greater than or equal to equation (12), it is optimal to offer a private agreement to firm i, in order to avoid going to the Patent Office's opposition system.

In the second equilibrium, the reaction function separates the regions in which firm $\mathrm{j}$ will or will not offer a private agreement. Firm $\mathrm{i}$ will resort to court action if the Patent Office returns an unfavorable verdict for firm i. The following equation describes such a reaction function. ${ }^{102}$

$\pi_{j}=\frac{\alpha \gamma(2-\gamma) \pi_{i}-(1+\gamma) C T_{A L}-(1-\gamma)\left[C T_{L}+C T_{w}\right]+T C}{\beta(1+\gamma+\delta-\delta \gamma)}$

Equation (13) suggests that firm $\mathrm{j}$ will offer a private agreement when the total profit is greater than or equal to the right side of the equation. Otherwise, firm $\mathrm{j}$ will prefer to await the Patent Office and court decisions.

With these equations, we are sufficiently able to determine the different equilibria for our model. Figure 10 allows us to analyze these equilibria by showing the decision curves for firm i and $\mathrm{j}$, as expressed by equations (10) and (11) for firm i, and (12) and (13) for firm j. As illustrated in Figure 10, ow the set of equilibria is more complex than in our previous situation where there was no Patent Office opposition system.

With the opposition system, two curves, representing equations (12) and (13), depict the optimal strategies for firm $\mathrm{j}$. In the area above each of these curves, firm j's optimal strategy is to offer a private agreement Below any of these curves, the optimal decision is to let the Patent Office or a court decide the dispute. When firm i does not resort to court, equation (12) represents firm j's decision curves (in Figure 10, it is the curve with the higher profit level). But, when firm i decides to resort to court, equation (13) represents the decision curve for firm $\mathrm{j}$ (in Figure 10, this is the lower curve). Figure 11 shows the set of equilibria we obtain from our model.

to Court, result 5, we obtain the same result as in equation (16).

101. See Equation 12, Appendix B.

102. See Equation 17, Appendix B. 


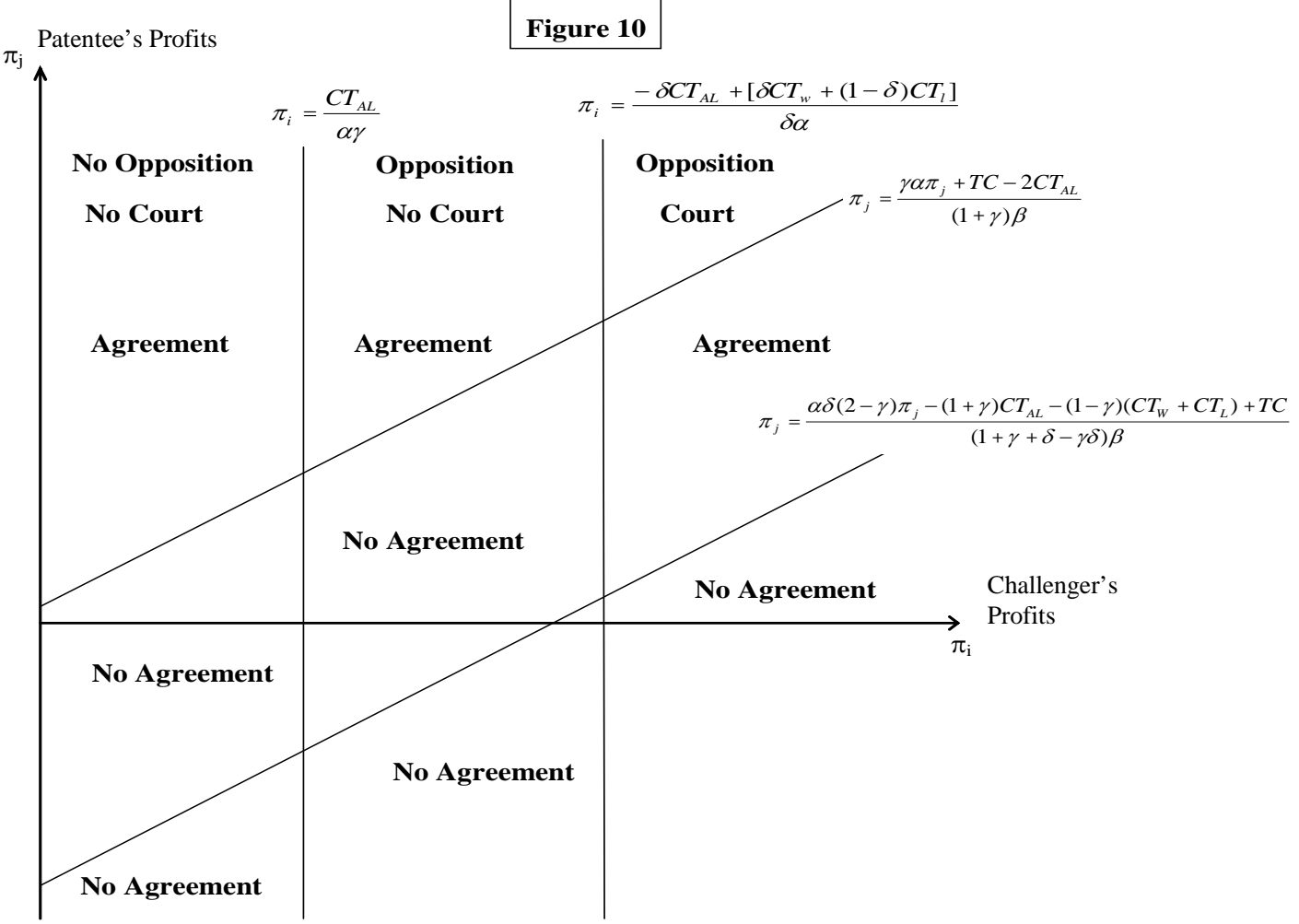

Figure 11

$\pi_{\mathrm{j}}$ Curve A

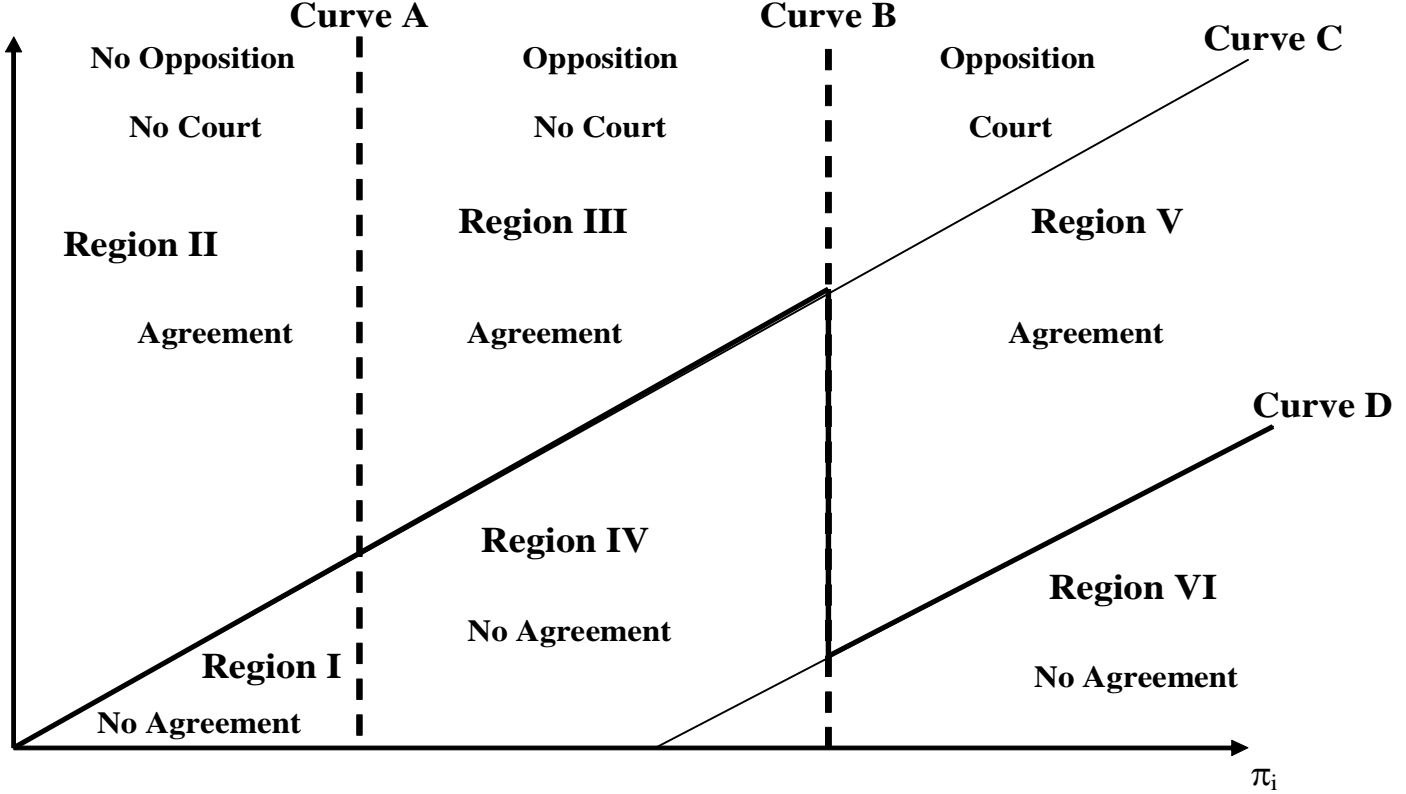


Figure 11 illustrates the different regions for each possible result. Curves A and B represent the decision curves for firm i. Curves $\mathrm{C}$ and $\mathrm{D}$ represent the decisions curves for firm $\mathrm{j}$. If the profit for firm $\mathrm{i}$ is lower than the level given by curve $\mathrm{A}$, then firm i's optimal strategy is not to resort to either the Patent Office or the courts. If the profit is between curves $\mathrm{A}$ and $\mathrm{B}$, then the optimal decision is to go to the Patent Office opposition system, but to not go to court. Finally, if the profit is greater than the level given by curve B, then the optimal strategy is to resort to both the Patent Office and court. For firm j, if its profit is above curve $\mathrm{C}$, and firm $\mathrm{i}$ does not go to court, then a private agreement is the optimal decision. If the level of profit is above curve $\mathrm{D}$, and firm i goes to court, then the optimal strategy is to offer a private agreement. (Observe that firm $\mathrm{j}$ switches from curve $\mathrm{C}$ to curve $\mathrm{D}$ as firm i's profit crosses above curve B. As a result, the decision curve for firm $\mathrm{j}$ is a broken curve, as shown by the bold curve in Figure 11. Accordingly, there are six possible results.)

In regions I and II, it is optimal for firm i to not resort to either the Patent Office or the courts. As a result, firm $\mathrm{j}$ will not offer a private agreement in any of the regions, even when it would be capable of offering one in region II. In region III, firm i now resorts to the Patent Office system and firm $\mathrm{j}$ is willing to provide a private agreement to Patent Office challenge. As a result, the solution is a private agreement between the parties. In region IV, firm i's optimal strategy is to go to the Patent Office, and firm j's optimal decision is to not offer a private agreement. Therefore, the Patent Office decides the validity of the patent. In region $\mathrm{V}$ of Figure 11, firm i is willing to resort to both the Patent Office and the courts. Moreover, firm $\mathrm{j}$ is willing to offer a private agreement. Consequently, the solution is a private agreement among the parties. Finally, in region VI, firm $\mathrm{i}$ resorts to action in the Patent Office and then in the courts. For firm $\mathrm{j}$, it is not optimal to offer a private solution. Rather, court action may be the preferred solution.

In this model, enhancing the Patent Office to provide an alternative opposition system expands the options outside the courts. The presence of this system could help to reduce the number of improvidently granted patents by offering a cheaper and more efficient alternative resolution methodoutside the court system. Figure 12 compares the model of this section with our pervious model without an opposition system. 


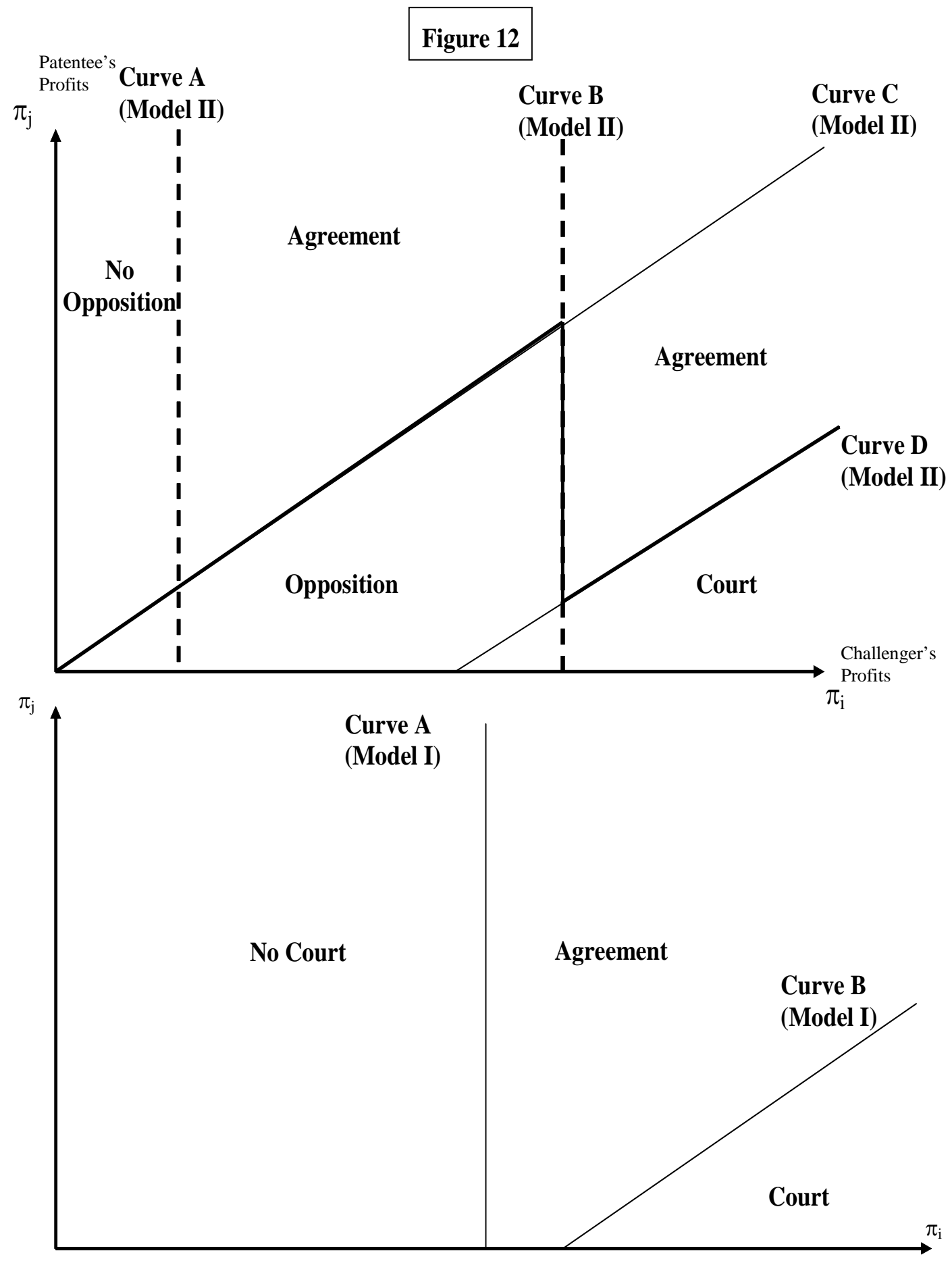


As Figure 12 shows, under the new system, fewer "bad" patents are not contested in the opposition system. Because it is less expensive, the opposition system may take the place of the courts or exist as an additional option in some cases. As a result, more patents will be contested under an opposition system than in the actual regime. Most of these patents are not being contested because of the costs associated with resorting to court action. Private agreements still exist, however, due to the particular cost structure and the incentives generated as indicated by the model. The number of private agreements will depend on the cost of the opposition system. If the Patent Office can offer an expeditious and inexpensive opposition procedure, few patents will be exclusively bargained for privately. In the following table, we summarize the differences among these systems.

Table 1: Model Comparison

\begin{tabular}{|l|l|l|}
\hline & $\begin{array}{l}\text { Patent Office without } \\
\text { Opposition }\end{array}$ & Patent Office with Opposition \\
\hline Cost of challenge & High & Low \\
\hline $\begin{array}{l}\text { Improperly granted } \\
\text { patent's chance of } \\
\text { survival }\end{array}$ & High & Low \\
\hline Court system & $\begin{array}{l}\text { Limited challenges in Patent } \\
\text { Office and courts are the } \\
\text { only challenge mechanism }\end{array}$ & $\begin{array}{l}\text { Fast and specific system- } \\
\text { complementary to the courts }\end{array}$ \\
\hline Incentives for patenting & High & $\begin{array}{l}\text { Lower than in the previous } \\
\text { situation }\end{array}$ \\
\hline Incentives for challenges & Low & High \\
\hline
\end{tabular}

\section{B. Characteristics of the New System}

The system analyzed in the previous section is an improvement from the actual system in which the Patent Office does not review patents and parties can only resolve disputes in court. The efficiency of the opposition system, however, depends on certain characteristics. Among these characteristics are the cost of the opposition system for both parties, how the Patent Office handles information from the parties, and the weight of Patent Office decisions with the courts. In this section, we analyze these requirements and directly refer to the main variables of the model developed in the previous section.

First, regarding the cost of the opposition system, it is crucial to provide an opposition service with costs lower than the court system and typical private agreements. If the cost of resorting to the Patent Office to challenge an incorrectly issued patent is much lower than the cost of reaching a private agreement, then there will be a higher probability of a challenge and lesser probability of survival of any "bad" patents. In our model, lower costs for the opposition system reduce the area of no opposition (Region I and II, Figure 11). Lower costs will increase the use of the opposition system and reduce the likelihood of reaching private 
agreements. As a result, we should expect a higher level of Patent Office opposition to improperly granted patents than under the patent current system.

Second, the Patent Office must design the opposition system with the goal of improving information access and efficiency. Under the opposition regime, it is important that the patentee has incentives to conduct searches of prior art before applying for the patent. Information gained from a prior art search would be valuable in the event of challenges arising under the opposition regime. This information would allow the Patent Office to accelerate the process and reduce the amount of work needed to make an informed decision. Another important aspect of the opposition system is its speed. In order to be efficient, the new regime should provide a limited amount of time for challenges to new patents. After this challenge time, it is the courts that decide future challenges. In doing so, the Patent Office minimizes the time during which there is uncertainty over the validity of the new patent. In order to provide potential challengers with fair access to the opposition system, the Patent Office should increase disclosure and make prior art information that has been considered readily available. The balance between these two factors is a key element in creating a well-working opposition system.

Third, Patent Office decisions may reduce the possibility of challenges in court. For example, if a patent is challenged in the Patent Office, and the Patent Office, after analyzing the case and gathering information, decides the patent is valid, then this determination may make the patent less vulnerable to attack. With this special protection, courts will have more information about the patent and its quality. Therefore, it should be more difficult to successfully challenge a patent previously ratified by the Patent Office. Furthermore, the Patent Office will reduce the work for the courts by providing reliable signals about the quality of a patent that has survived an opposition. In our model, when the Patent Office validates a challenged patent, the validation decreases the probability of success for the challenger in court. As a result, we should expect that challengers will be discouraged from going to court after the Patent Office has rejected their claims, unless they have good cause.

\section{Pre-grant or Post-grant Procedure}

Designing an opposition system for the Patent Office requires considering different issues that affect the efficiency of the system. One of these issues is choosing between a pre-grant or post-grant system. ${ }^{103}$ While both systems have distinct advantages and disadvantages, post-grant systems are in place in most of the international patent offices such as Japan, Germany, and the European Union. ${ }^{104}$

Pre-grant systems have considerable advantages. First, the Patent Office has more incentive to analyze the opposition claim objectively. ${ }^{105}$ Generally, in postgrant systems, it is difficult for organization members to reject a patent that they

103. See Kesan, supra note 1 , at 158 (describing both types of systems).

104. See Allan Soobert, Breaking New Grounds in Administrative Revocation of U.S. Patents: A proposition for Opposition and Beyond, 14 SANTA Clara COMPuTER \& High TeCH. L. J. 63 , 63 (1998) (describing the patent and opposition systems in the European Union and Japan). See Mark D. Janis, Rethinking Reexamination: Toward a Viable Administrative Revocation System for U.S. Patent Law, 11 HARV. J. L. \& TECH. 1, at 102-17 (1997) (comparing the European patent reexamination systems with the U.S.).

105. See Kesan, supra note 1 , at 778. 
have already granted. ${ }^{106}$ As a result, the pre-grant systems provide better possibilities than post-grant systems that claims will be treated fairly. ${ }^{107}$ Second, once the Patent Office grants the patent, its validity is stronger because it has obtained approval not just from the issuing office, but also from the opposition system. ${ }^{108}$ As a result, we should expect that this validity will be helpful for further challenges in court. Third, since the patent is not yet granted, individual inventors or firms have to use the opposition system instead of resorting to the courts. ${ }^{109}$ For example, in Japan and Germany, the change from a pre-grant opposition system to a post-grant system produced an increase in the number of court cases and a decrease in the number of oppositions. ${ }^{110}$

Pre-grant systems also have many disadvantages. First, firms with high levels of resources and power will more frequently oppose small inventors in an attempt to block their patents. ${ }^{111}$ For the Japanese patent office, the change to a post-grant system was the result of complaints and a strong lobby by American firms that felt Japanese firms were using the pre-grant system to block their inventions. $^{112}$ Second, the early information disclosure needed for a pre-grant system may provide otherwise secret information to the patentee's competitors. ${ }^{113}$ As an example, this could induce competitors to act strategically and invest in a given technology. ${ }^{114}$ Defenders of early disclosure systems also believe that the early disclosure of information encourages technological advances. ${ }^{115}$ Third, competitors may try to save costs and hold-back potentially invalidating prior art in a pre-grant opposition system and just wait for the patent to issue.

The disadvantages of the pre-grant system can be ameliorated by: (1) taking specific measures to avoid excessive oppositions that attempt to block a new technology, such as limiting the number of oppositions that may be filed by a third party, forbidding repeated oppositions based merely on cumulative evidence, creating pre-grant oppositions only for anticipatory evidence and the like; and (2)

\footnotetext{
106. Id.

107. Id.

108. Id.

109. "Data from Germany and Japan for both their pre-grant and post-grant opposition systems suggests that opponents perceive pre-grant oppositions to be more effective in comparison to post-grant systems.... The data shows that patents are more likely to be challenged in a pre-grant opposition system compared to a post-grant system." Kesan, supra note 1, at 781.

110. Id.

111. See Kesan, supra note 1 , at 779 .

112. Id.

113. Id. at 778

114. Id.

115. "[E]arly disclosure maximizes economic value of the patent system by promoting disclosure which is likely to lead further advances in the technology. Proponents also point to the fact that the U.S. patent system remains the only system of significance that does not require early disclosure for all patent applications." Id. at 777

"The advantages of publication cannot be overestimated: First, secrecy as we know it today does not promote the progress of useful arts. Others working in the relevant field need to know as early as possible what is likely to be protected in order to avoid poor research and development investments and to have an explanation of the technology in order to improve upon it. Encouraging these technological improvements is one of the main reasons all other industrialized countries provide early publication. Second, given the challenges of our present system, another very important advantage of publication is that it would give parties the opportunity to inform the PTO about the relevant prior art. Thus, publication will enable the PTO to provide higher quality examination at less cost, resulting in higher quality patents." Nancy J. Lick, Kevin T. Kramer\& David J. Ball, Jr., A New Patent Examination System for the New Millennium, 35 Hous. L. REV. 305, 318 (1998).
} 
publishing the prior art cited by the Patent Office in its office actions with the patent application. ${ }^{116}$

Post-grant opposition systems also have many advantages. First, because there is no requirement for information disclosure early in the granting process, the inventors' technology remains protected. ${ }^{117}$ Second, firms cannot use the opposition system to block the grant of competitors' patents. ${ }^{118}$ Challenging a patent is only available after the patent is granted, thus avoiding this problem of pre-grant systems. Third, for some patents, the decision to challenge a patent can change over time. For example, a firm can patent an obvious technology that is not challenged initially because of the small value of the patent. Later, however, this patent could become both valuable and harmful to competing firms. Therefore, having a post-grant system could help provide an inexpensive challenge system for some time after a patent is issued. Nonetheless, for any pre-grant or post-grant system, challengers may still contest a "bad" patent in court.

Post-grant opposition systems also have disadvantages. First, the Patent Office's has an incentive to reject the opposition in order to protect its first decision to grant the patent. For post-grant systems, there is an inherent conflict in the management of the system because the same group/office in charge of granting the patent has to now take steps to review its validity. ${ }^{19}$ As a result, the examiners will be more willing to reject claims questioning the validity of a patent that they have approved. ${ }^{120}$ This problem can be ameliorated by appointing an opposition panel with Administrative Opposition Judges (AOJs) that are independent from the Patent Office examining corps. ${ }^{121}$ Second, once a patent is granted, oppositions may occur less frequently. ${ }^{122}$ As a result, it is difficult for the challenger to obtain a successful review of a granted patent.

Based on a careful assessment of the advantages and disadvantages of both systems, most observers prefer a post-grant opposition system over a pre-grant system. ${ }^{123}$

\section{Scope of Estoppel and Type of Procedure}

Another important characteristic of the opposition system is the scope of estoppel, i.e., to what extent does the verdict of an opposition panel block any further action in the courts. ${ }^{124}$ At one extreme, a system might permit the

\footnotetext{
116. Id.

117. See Kesan, supra note 1 , at 779 .

118. Id.

119. Id.

120. "The concern is that the examiner is not likely to concede that the outcome of her examination was incorrect and that the patent should not have been granted." Id. at 778 .

121. Id. "European opposition proceedings are not conceptualized as an extension of the examination process. Having no need to maintain the fiction of a new examination, the EPO has entrusted the adjudication of oppositions to an administrative panel, not to individual examiners as is the case with U.S. reexamination. This is a further indication that, at a minimum, the practice of forcing individual examiners to adjudicate inter partes patent validity proceedings should be discarded even if the proposed reexamination reform legislation passes." Janis, supra note 104, at 102-03.

122. Kesan, supra note 1 , at 781-82.

123. "[T]he United States should adopt a true inter partes administrative revocation system that reflects the lessons from the European Patent Convention post-grant opposition practice and U.S. trademark inter partes administrative procedures (opposition and cancellation)." Janis, supra note 104, at 118.

124. Under the actual U.S. system, the type of estoppel is biased towards the courts. "[T]he PTO's affirmation of a patent's validity in reexamination is not binding on the court because the standards of proof are different. Thus, even if a patent is confirmed by EPR [Ex- Ante Reexamination], a challenger could assail
} 
presentation of any type of claim in court after the opposition is completed. ${ }^{125}$ At the other extreme, a system might prohibit the continued prosecution of any claim in court. In the first instance, the absence of any estoppel creates a problem for the patentee and for the validity of the opposition system. If the opposition system does not inform court action, or at least improve the chances of the patentee in court after successfully defending her patent, then it is useless as an instrument to assess the validity of patents. In the second case, if the challenger is not able to prosecute his claim in court, then the system is reduced to a one-shot game without further review. Instead of resorting to any extreme estoppel or lack thereof, we suggest using an intermediate solution, where the opposition system generates a judicial precedent but does not prohibit the challenger from seeking judicial review. ${ }^{126}$

In our model, we can introduce the level of estoppel by adding an extra parameter in the payoff of the challenger. If the challenger decides to go to court, the parameter $\varepsilon$ measures the accessibility of the courts. If $\varepsilon=1$, then the courts are widely available, indicating a lack of estoppel. However, if $\varepsilon=0$, then the estoppel is complete, since the challenger cannot access the courts. Graphically, Figure 13 shows the effect of the introduction of estoppel. If there is no estoppel, the challenger can resort to the courts after using the opposition system. This generates a similar situation to our model with six different equilibria. If, however, there is a complete estoppel, the challenger cannot resort to the courts after the opposition system renders its verdict. As a result, the system is reduced to using only the opposition system, and the number of equilibria is down to four. In reality, we should expect the estoppel to be complete in some aspects and incomplete in other aspects. For example, the challenger may have to overcome a higher threshold of proof in court if his invalidation challenges are based on the same prior art previously considered in the opposition. Yet, the patentee can be freely challenged on any other argument or issue not raised in the opposition proceedings.

\footnotetext{
the patent again in court. To be sure, that the patent has been reexamined and approved by the PTO twice would be compelling evidence for a court or jury to uphold its validity. Conversely, a court's invalidation of a patent -a challenger sustains the $\S 282$ burden of proof -may trigger collateral estoppel and bind the PTO. The result is different here because the courts are 'the final authorities on issues of statutory construction'.... Once a court determines that a third party requester meets the statutory burden of invalidating a patent, the PTO may not reverse that decision. ... Lastly, the cancellation of a patent by the PTO, the result most desired by challengers, would most likely persuade the court to dismiss the plaintiff-patentee's complaint, as the case would no longer be grounded upon a valid patent." Allen M. Leung, Legal Judo: Strategic Application of Reexamination Versus an Aggressive Adversary (Part I), 84 J. PAT. \& TRAdEMARK OfF. SOC'Y 471, 484-85 (2002).

125. "The reform legislation also alters the estoppel effect of PTO reexamination determinations in pending or subsequent litigation. A proposed provision would establish that once a third party participates as a party to an appeal from an examiner's reexamination determination, the third party is estopped "from asserting at a later time, in any forum, the invalidity of any claim determined to be patentable on appeal on any ground which the third-party requester raised or could have raised during the reexamination proceedings." This also reverses prior law in that a PTO confirmation of patentability (once made final) can now potentially estop a third-party requester from renewing the same validity challenge in court." Janis, supra note 104, at 85-86 (discussing the proposed legislation on the reform of the Patent Office).

126. "As envisioned, a third party that requests reexamination would be estopped from later raising in court any issue raised, or that could have been raised during reexamination. This estoppel provision is presently part of the proposed legislation. Clearly, such a provision would help to unburden the courts. Such a provision would also help to prevent repeated harassment of patentees." Lick et. al., supra note 115, at 325.
} 
Another important characteristic of the opposition system is the type of procedure, i.e., written submissions/briefs or procedures with live testimony, to be employed by the opposition system. ${ }^{127}$ For a system making decisions by only reviewing written documents, the evidence can be handled and revised more quickly, and the costs of the opposition system are small. In the second case, a system that authorizes full hearings and live testimony for oppositions is more burdensome and can increase the costs of the opposition. ${ }^{128}$

As we saw in our model, the desirability of using the opposition system depends significantly on it being less costly than the courts. As a consequence, we should design a low-cost revocation system for patents in order to create a successful alternative system to the courts. Otherwise, the increase in the costs of using the opposition system will have a negative impact on the efficiency of the overall examination procedures.

\section{E. Fee Shifting}

The type of fee schedule utilized can enhance the creation of an opposition system and the incentives that patentees and challengers face. As proposed elsewhere, ${ }^{129}$ the incorporation of a system with fee-shifting for patent challenges will increase the number of challenges, changing the incentives for patentees and challengers. In particular, if we wish to induce validity challenges, we might consider a one-way, pro-defendant/challenger, fee shifting system if a patent is invalidated or revoked in litigation or opposition proceedings. ${ }^{130}$ For patentees, the existence of a low cost opposition system, and the possibility of having to pay the full cost of using such a system or the full cost of a court proceeding will increase the incentives for procuring better patents with a lower probability of being challenged. For challengers, the existence of a low cost opposition system and the possibility of a "free" opposition procedure for cases when the patent is found to be invalid will increase the willingness to challenge invalid patents.

According to our model, the change to a one-way fee shifting system will increase the payoff for challengers who are successful in revoking a patent. Accordingly, it will also increase the cost for patentees who lose in such a process. As a result, challengers will have more incentives to resort to the opposition system or the courts. This will reduce the areas in which the challenger does not resort to any action and further enhance the possibility of challenges to invalid patents. In Figure 11, that means a movement of the lines for $\pi_{\mathrm{i}}$ to the left, reducing the area of no action by complainants. As a result, the implementation of

127. "Though oral hearings are admittedly an uneconomical type of proceeding, the JPO appeal process is especially inefficient." Masaya Suzuki, The Trademark Registration system in Japan: A Firsthand Review and Exposition, 5 MARQ. INTELL. Prop. L. R. 133, 147 (2001) (discussing the performance of the Japanese system).

128. "Long delays in the Japanese legal system work against the disposition of cases through court decisions. In Japan, it is impossible to get a hearing at which all issues can be discussed at one time. Usually, a series of hearings, typically lasting only minutes, are conducted at monthly intervals. The parties submit evidence in writing, after which the court may require oral presentations. Changes in or transfers of a member of the three-judge panel may delay the process further by making it necessary to repeat oral presentations. Moreover, only the JPO has the authority to decide issues of invalidity of a patent raised as a defense. Where such a defense is raised, the courts often suspend the infringement litigation. This suspension results in 'considerable delay.' Delays of up to ten years have been reported." Nancy Linck and John McGarry, Patent Procurement and Enforcement in Japan, a Trade Barrier, 27 GEO. WASH. J. INT'L L. \& ECON. 411, 422-23 (1993-1994).

129. See Kesan, supra note 1 , at 786.

130. Id. 
a one-way fee shifting regime will enhance the scope of the region wherein an opposition process becomes a viable option for a challenger. 


\section{Figure 13}

Patentee's

Profits

\section{Absence of Estoppel}

$\pi_{\mathrm{j}}$

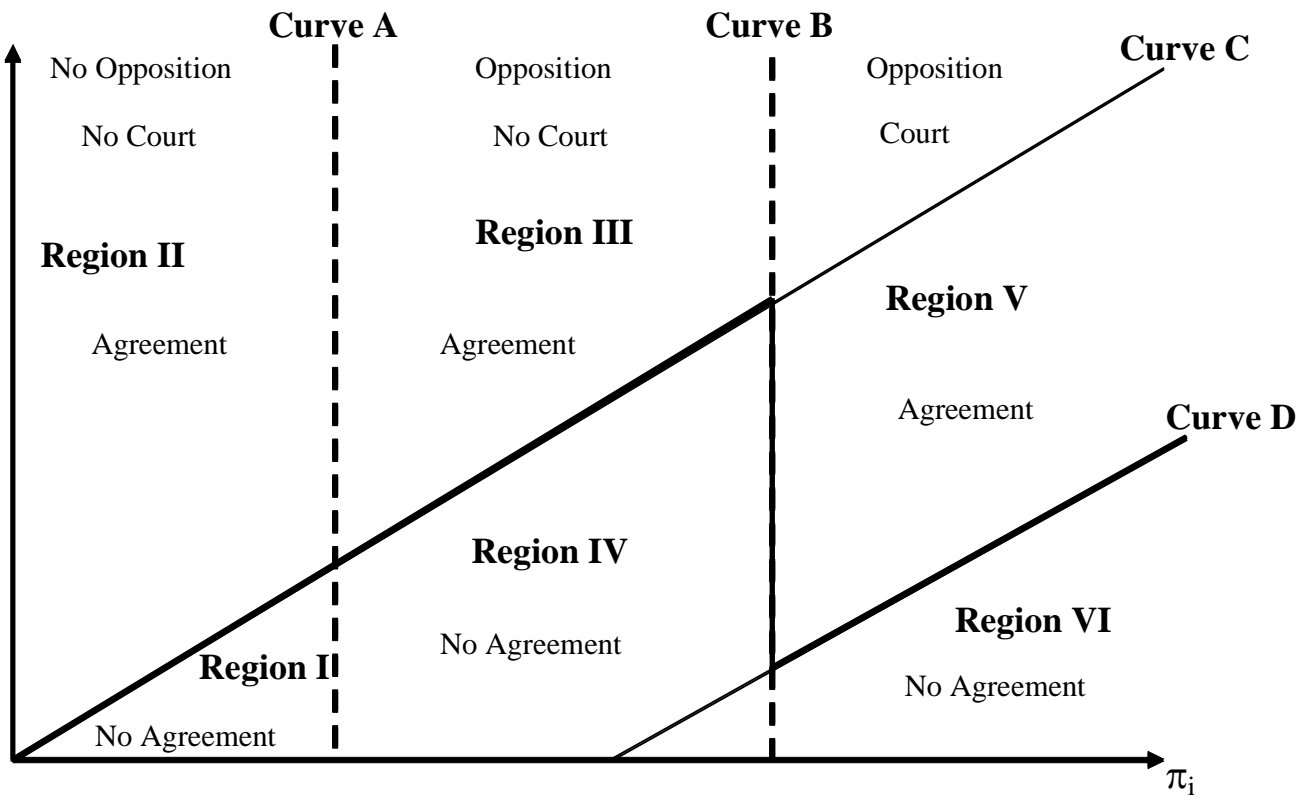

Challenger's Profits

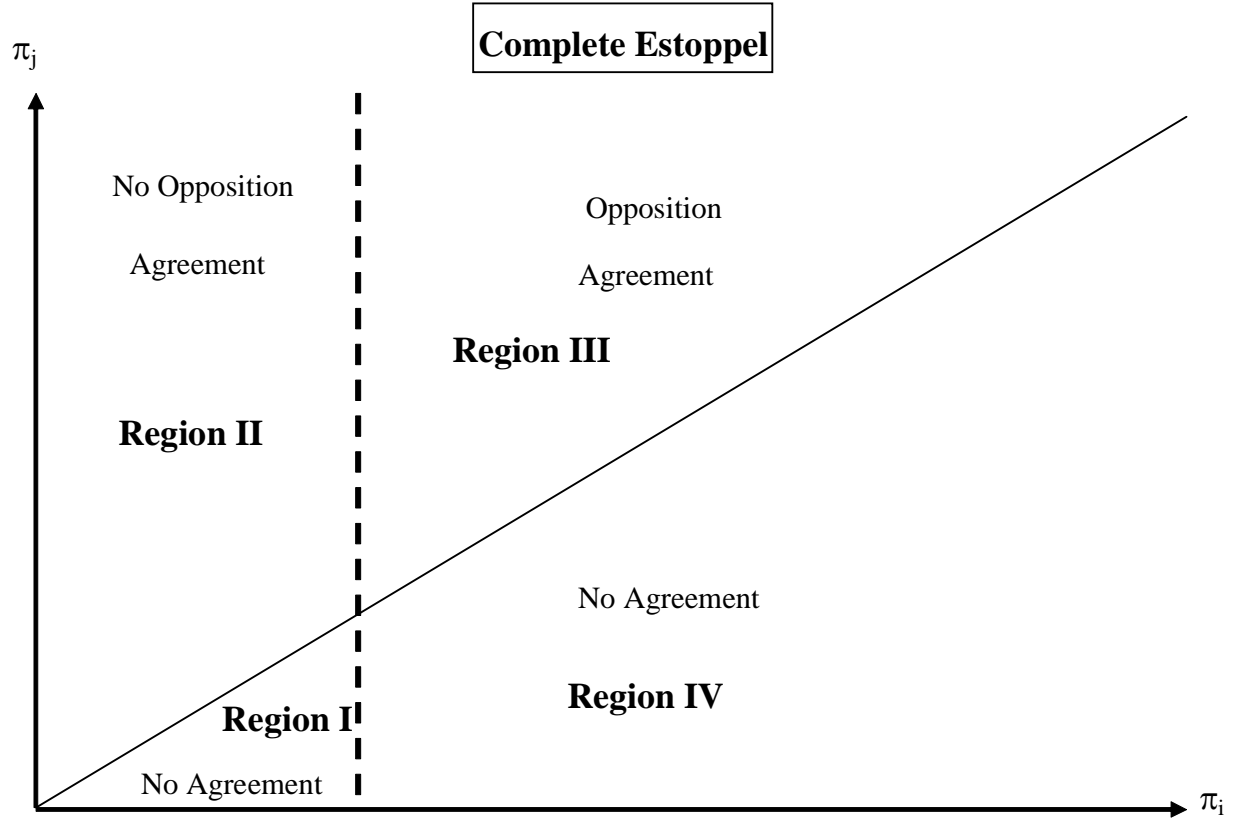




\section{Patent InVAlidation Processes in the JPO AND the JaPANese Courts}

In the previous sections, we have seen how a carefully-designed opposition process in the Patent Office can increase both the probability of a third-party challenge to an issued patent and the probability of obtaining a decision on the merits regarding validity in the context of such a challenge. In the past five years, Japan has been experimenting with a dual patent invalidation process that permits issued patents to be challenged in the JPO and the Japanese courts.

In Japan, prior to 2000, in patent infringement litigation, it was presumed that issued patents should be regarded as valid until such time as the Japanese Patent Office (JPO) determines invalidity and revokes an issued patent. In April 2000, the Supreme Court of Japan, in the Kilby decision, determined that courts can consider the validity of patents in infringement cases in certain circumstances and revoked the teachings of conflicting precedents. ${ }^{131}$ In Kilby, the Supreme Court of Japan concluded that when the likelihood of a patent being found to be invalid is quite high, the exercise of that patent constitutes an "abuse of the patent right" and should therefore be prohibited by the court. ${ }^{132}$ To clarify, the term "abuse of patent right" is not similar or related to the patent misuse doctrine in the U.S. This term simply refers to patent invalidation in the courts in Japan. In this context, the term "invalidation" is not used because patent validity is purely a matter for the JPO under Japanese Patent Law. Hence, the Japanese Supreme Court in the Kilby decision chose to refer to patent invalidation by the courts as arising from an abuse of the patent right that required correction by the courts.

Until recently, the Japanese Patent Office had provided two mechanisms for challenging issued patents through a post-grant opposition system and a trial for invalidation system. The two mechanisms have now been merged into a single trial for invalidation procedure in the JPO that provides opportunities for third parties to administratively challenge issued patents.

In this section, we will present a comparative assessment of the patent invalidation procedures adopted by the JPO and the "abuse of patent right" process in the Japanese District Courts. Table I below summarizes the key differences and highlights the similarities as well.

131. Texas Instruments Inc. v. Fujitsu, Ltd., Case (O) 364/1998, Supreme Court of Japan, April 2000 (permitting patent invalidation by Japanese courts as an abuse of the patent right).

132. $I d$. 
Table I: A Comparison of Patent Invalidation Procedures in the Japanese Patent Office (JPO) and the District Courts in Japan

\begin{tabular}{|c|c|c|}
\hline & $\begin{array}{l}\text { Trial for Invalidation } \\
\text { in JPO }\end{array}$ & $\begin{array}{l}\text { "Abuse of Patent Right" } \\
\text { in District Court }\end{array}$ \\
\hline $\begin{array}{l}\text { Who Can Raise } \\
\text { Invalidation Claims }\end{array}$ & Anyone and at anytime & $\begin{array}{l}\text { Only in a infringement } \\
\text { action or declaratory judgment } \\
\text { action }\end{array}$ \\
\hline $\begin{array}{l}\text { Grounds for } \\
\text { Invalidation }\end{array}$ & $\begin{array}{l}\text { JPO seen to be better at dealing } \\
\text { with patentability standards that } \\
\text { are familiar to them }\end{array}$ & All grounds available \\
\hline $\begin{array}{l}\text { Standard for } \\
\text { Invalidation }\end{array}$ & Basic patentability standards & $\begin{array}{l}\text { The invalidation standard may } \\
\text { be theoretically higher } \\
\text { requiring "obvious invalidity," } \\
\text { but practically, the standard } \\
\text { may not be very different from } \\
\text { the JPO }\end{array}$ \\
\hline $\begin{array}{l}\text { Cost of Invalidation } \\
\text { Process }\end{array}$ & Relatively low & Significantly higher \\
\hline $\begin{array}{l}\text { Duration for } \\
\text { Invalidation Process }\end{array}$ & About one year & $\begin{array}{l}\text { About } 15-16 \text { months, but the } \\
\text { time period is going } \\
\text { down }\end{array}$ \\
\hline $\begin{array}{l}\text { Evidence } \\
\text { Considered }\end{array}$ & $\begin{array}{l}\text { Evidence presented by the } \\
\text { parties, but Trial Examiner can } \\
\text { uncover their own evidence by } \\
\text { conducting own search }\end{array}$ & What is presented by the parties \\
\hline Effect of Judgment & $\begin{array}{l}\text { Judgment is effective against the } \\
\text { public at large, and the scope of } \\
\text { protection can be made narrower } \\
\text { by issuing newer claims }\end{array}$ & $\begin{array}{l}\text { Judgment binding on the parties } \\
\text { only, and narrower claims are } \\
\text { not issued by the court }\end{array}$ \\
\hline Decision-Maker & $\begin{array}{l}3 \text { Trial Examiner panel or } 5 \text { Trial } \\
\text { Examiner panel }\end{array}$ & $\begin{array}{l}\text { District Court Judge with } \\
\text { Technical Assistants }\end{array}$ \\
\hline Appeal of Judgment & Can appeal to the High Court & $\begin{array}{l}\text { Can appeal to the High } \\
\text { Court }\end{array}$ \\
\hline Damages & Cannot award damages & Can award damages \\
\hline
\end{tabular}

There are several points in the comparison table shown above that are worthy of careful consideration and emphasis. The JPO trial for invalidation is a relatively low cost process. The Japan Patent Attorneys Association’s survey in 2003 reports an average cost of $¥ 377,534$ (about $\$ 3,500$ ) on a per claim basis for a JPO invalidation trial for with over $75 \%$ of those responding to the survey reporting an average fee in the range from $¥ 360,000$ to $¥ 420,000$. One can get some insight into what a patent trial is likely to cost in Japan based on the Civil Litigation Lawyers' Fees Guidelines that are put forth by the Japan Federation of Bar Associations (Nichibenren). They suggest that if the plaintiff's demand for damages is in the ¥30-300 million range, then the starting fee is [3\% + ¥690,000] and the success fee is $[6 \%+¥ 1,380,000]$, which amounts to about $\$ 325,000$ in lawyers' fees for a successful patent lawsuit involving about $\$ 3,000,000$ in 
damages. In sum, the typical cost for a patent trial in court costs can be as much as hundred times more expensive than a trial for invalidation in the JPO.

The JPO trial for invalidation is open to anyone at anytime, as opposed to a court process that comes about in the context of a infringement trial or declaratory judgment action. With respect to the grounds for challenging an issued patent, there is much greater confidence in the JPO's ability to handle issues related to patentability such as novelty, lack of inventive step, and industrial applicabilitymatters that are routinely dealt with by patent examiners, as opposed to other invalidations based on prior sales or public use and the like, involving forms of evidence different from prior art patents or publications. In addition, the JPO panel is not limited to evidence that is presented to it by the parties, as the trial examiners may conduct their own prior art search, if they deem it necessary. Hence, the trial for invalidation in the JPO, which is a significantly lower cost process, is favored by third-parties especially if their validity challenges are based on lack of novelty or obviousness.

The duration of a typical patent trial in Japan is currently about 15-16 months, but the durations are decreasing and heading towards one year. Therefore, these times are comparable to the one year duration for a trial for invalidation in the JPO. Thus, in the more recent past, the Japanese courts have had the benefit of rulings on validity by the JPO prior to their own consideration of patent validity in the same dispute.

There are also other procedural differences, such as the effect of the judgment being different in the two cases because the court decision is binding on only the parties, whereas patent invalidation in the JPO is effective against the public at large. In addition, the decision maker in the JPO may be a panel of trial examiners instead of a single district court judge. The District Court judge is assisted in his evaluations by a technical assistant who is typically a former trial examiner in the JPO and who has been sent to the courts by the JPO for a period of about three years. This practice does not appear to pose any separation of powers concerns in Japan since the distinction between public servants versus private attorneys in Japan seems to be more important than any institutional separation between the governmental agencies and the courts. Finally, judgments from both the JPO and the District Court can be appealed to the High Court for appellate review.

There does not appear to be a mechanism in place to prevent repeated filings of trials for invalidation in the JPO by challengers who wish to simply present repeated claims in the hope of successfully invalidating one or more claims in a patent. In the future, it may be worthwhile to consider mechanisms or schemes to create an incentive for a challenger to present all his claims in one trial for inval dation and to avoid repeated challenges based on "new" prior art that is merely cumulative compared to what was presented in an earlier challenge.

Tables II and III summarize the empirical data resulting from the dual inval dation system in the JPO and the district courts since April 2000 to the present day. We can see that in $69 \%$ of all patent lawsuits in district court, invalidity was an issue raised in either the JPO or the district court or in both forums. Of this $69 \%$, only in $7 \%$ of the cases was patent invalidation raised only at the district court. Therefore, in (62/69)\%, i.e., in about $90 \%$ of all cases involving patent invalidity, a trial for invalidation was initiated in the JPO. In addition, in about $48 \%$ of all cases involving patent invalidity claims, the invalidity issues were 
presented to both the JPO and the district court. As noted above, in only about $10 \%(7 / 69)$ of all the cases involving patent invalidity was the invalidation challenge presented exclusively to the District Court. This data demonstrates that even with the more recent possibility of court invalidation challenges the trial for invalidation is seen to be a reliable and efficient way to challenge patents in Japan.

Table III examines the consistency in outcomes when the same patents are challenged in both the JPO and the District Court over a three year period from April 2000 to November 2003. In the vast majority of cases (about $80 \%$ ), both the JPO and the District Court are in agreement. In about 19.7\% (14/71) of the cases, the JPO and the District Court reached different outcomes on judgments regarding the validity of the same patent claims. While this difference of judgment and opinion may be significant, both decisions can be appealed to the High Court, and hence, the two outcomes can be reconciled at the appellate level. In addition, this difference of opinion in about $20 \%$ of the cases is roughly comparable to the percentage of reversals of the JPO in appeals to the High Court (about 18.2\%). In short, the different outcomes in about $20 \%$ of the cases is understandable and may be attributable to the structural and institutional differences between the Patent Office and a court in examining the evidence that is presented. This result also suggests that both institutions are acting quite prudently in resolving patent validity issues.

\section{Table II: The Different Categories of Actions taken in 270 District Court Patent Cases with respect to Invalidation Trials in the JPO from April 2000 to November 2003}

$31 \%$ (84 cases) - Infringement action only in District Court
$33 \%$ - Invalidation Trial in JPO \& “Abuse of Patent Right" claim in District Court
$29 \%$ - Invalidation Trial only in JPO
$7 \%$ - "Abuse of Patent Right" only in District Court

Table III: Comparison of 71 JPO and District Court Decisions Regarding Patent Invalidity from April 2000 to November 2003

\begin{tabular}{|c|c|c|c|c|}
\hline & & & District Court & \\
\hline & & Valid & & Invalid \\
\hline & Valid & 18 & & 5 \\
\hline \multirow[t]{2}{*}{ JPO } & & & & \\
\hline & Invalid & 9 & & 39 \\
\hline
\end{tabular}


There is much to be learned from the details of the two patent invalidation processes and from the empirical data presented above. This dual track invalidation system in Japan involving both the JPO and the district courts demonstrates that both invalidation schemes are complementary and serve to increase the universe of issued patents that are challenged by third parties. The specific differences between the two invalidation options that are described above indicate that while a patent may be challenged in both venues in the vast majority of cases, there are sound economic and institutional reasons for maintaining (or creating) a patent system with the ability to raise patent validity challenges in both the Patent Office and in the courts.

\section{CONCLUSIONS}

There is significant concern from both sides of the aisle that the USPTO grants many overbroad patents. For instance, the Internet and software sectors have created a very dynamic environment for patenting. New firms are trying to control markets and construct corporations based on multiple patents in different aspects of Internet transactions. Furthermore, with patents now including business methods, many software and Internet firms have found this new area very accommodating for patenting. Nonetheless, many authors and commentators have cited these new areas as key sectors where the number of improvidently granted patents has increased.

In this paper, we constructed a formal model of our current patent system that illustrates how "bad" patents can survive in the market. We showed that the patent system cannot rely on the judicial system as the only safeguard against low quality patents.

As we have demonstrated using our model, improvidently granting a patent (i.e., issuing a "bad" patent) will produce three possible market outcomes: (a) survival as any other patent; (b) survival with a private agreement with the possible challengers; or (c) invalidation of the "bad" patent by a court; each with a given probability. Consequently, judicial processes and market forces do not necessarily extinguish incorrectly granted patent claims. Rather, these patents can survive and impose significant social costs.

We also analyze how changes in judicial costs, court performance, and private transaction costs affect the probability of survival for a "bad" patent. As expected, higher litigation costs induce private parties not to resort to the courts. Instead, private parties solve patent problems by themselves or to let the "bad" patent's validity remain unchallenged. Court performance is crucial in determining the probability of a "bad" patent being challenged in court. Higher efficiency in determining and invalidating "bad" patents induces firms to use the court system more frequently in resolving their differences. Increases in private transaction costs also reduce reliance on the courts.

Given the high costs of going to court, our current patent system's choice of allowing the courts to decide these disputes concerning incorrectly granted patents is not optimal. As a result, improving the quality of the patent granting process at the Patent Office should provide the most efficiency for society. The introduction 
of an opposition system inside the Patent Office would provide an excellent way to reduce the number of "bad" patents at a low cost.

We then expanded our model to include the possibility of an administrative opposition system inside the Patent Office. This opposition system is intended to provide a fast and low-cost review of patents that have been recently granted. Using this model, we show that the existence of such a system greatly improves the performance of the patent system by reducing the number of "bad" patents surviving without challenge and lowering the high litigation costs of traditional court challenges.

Next, we discussed how the different characteristics of the opposition system will determine the chances of a successful reform. The design of the opposition system should focus on providing a low cost and effective procedure for challenging patents. As we showed, the type of system, i.e., pre- or post-grant opposition, the scope of estoppel, the type of procedures employed in the opposition, and the implementation of a one-way fee-shifting procedure are factors that will determine the efficiency of the proposed reform. Our model and the discussion comparing different systems suggests that a post-grant opposition system with an effective level of estoppel, concentrated around the issues brought to the opposition panel, will provide the basis for an effective and low-cost regime. ${ }^{13}$

Finally, we compared the insights gained from our theoretical analysis with recent empirical data from Japan, which has embarked on a fascinating experiment and implemented a dual patent invalidation system employing both the Japanese court system and the JPO. Their experience demonstrates that both invalidation mechanisms are complementary and serve to increase the number of issued patents that are challenged by third parties. The specific differences between the two invalidation options indicate that while a patent may be challenged in both venues in the vast majority of cases, there are sound economic and institutional reasons for creating a patent system with the ability to raise patent validity challenges in both the Patent Office and in the courts.

133. The issues include, for example, a swift proceeding allowing written submissions/briefs. 


\section{APPENDIX A}

\section{A. Payoffs}

Firm i payoffs,

$$
P=\delta\left(\alpha \pi_{i}-C T_{w}^{i}\right)-(1-\delta)\left(C T_{l}^{i}\right)
$$

Where: $\mathrm{P}$ is the expected payoff for firm i.

$\delta$ is the probability of winning the trial,

$\alpha \pi_{\mathrm{i}}$ is the fraction of firm i profits lost because of the existence of the new patent.

We assume $\alpha<1$

$\mathrm{CT}_{\mathrm{w}}^{\mathrm{i}}$ is the cost of resorting to court, given that firm i wins at trial,

$\mathrm{CT}_{1}^{\mathrm{i}}$ is the cost of resorting to court, given that firm i loses at trial.

Equation (1) is the expected payoff if firm $\mathrm{i}$ decides to go to court. If firm $\mathrm{i}$ decides not to resort to court, the payoff is:

$P=0$

In order to go to court, the expected payoff for resorting to a trial should be greater or equal to the payoff of not challenging the patent. From equation (1) and (2), we obtain the following condition:

$\delta\left(\alpha \pi_{i}-C T_{w}^{i}\right)-(1-\delta)\left(C T_{l}^{i}\right)=-\alpha \pi_{i}$

$\alpha \delta \pi_{i}-\delta C T_{w}^{i}-C T_{l}^{i}(1-\delta)_{i}=-\alpha \pi_{i}$

Symplifying

$\delta \alpha \pi_{i}-\left(\delta C T_{w}^{i}+(1-\delta) C T_{l}^{i}\right)=0$

Then,

$\begin{array}{ll}\delta \alpha \pi_{i} \geq \delta C T_{w}^{i}+(1-\delta) C T_{l}^{i} & \text { (Goes to Court) } \\ \delta \alpha \pi_{i} \leq \delta C T_{w}^{i}+(1-\delta) C T_{l}^{i} & \text { (Does not go to Court) }\end{array}$

From (3) solving for $\pi_{\mathrm{i}}$,

$\pi_{i}=\frac{\delta C T_{w}+(1-\delta) C T_{l}}{\delta \alpha}$

In case firm i's optimal response is to go to court, firm j, i.e., the patentee, can offer a private solution in order to avoid court action. 
$(1+\delta) \alpha \pi_{i}-\theta \leq \delta C T_{w}^{i}+(1-\delta) C T_{l}^{i}$

rearranging,

$\theta \geq(1+\delta) \alpha \pi_{i}-\delta C T_{w}^{i}-(1-\delta) C T_{l}^{i}$

Firm j's payoff is given by the following:

$P=\beta \pi_{j} \quad$ (Patent is not contested in Court)

$P=(1-\delta)\left(-\delta C T_{w}^{j}\right)-\delta\left(C T_{l}^{j}+\beta \pi_{j}\right) \quad$ (Patent is contested by firm i)

Where, $\beta \pi_{\mathrm{j}}$ is the monopoly profits received by the firm from the patent;

$(1-\delta)$ is the probability of winning the trial;

$\mathrm{CT}_{\mathrm{w}}{ }_{\mathrm{j}}^{\mathrm{j}}$ are the court costs when the patentee wins the trial; and

$\mathrm{CT}_{1}^{\mathrm{j}}$ are the court costs when the patentee loses the trial.

Accordingly, firm $\mathrm{j}$ will prefer its patent not to be contested in court when:

$\beta \pi_{j} \geq(1-\delta)\left(-C T_{w}^{j}\right)-\delta\left(C T_{l}^{j}+\beta \pi_{j}\right)$

or

$(1+\delta) \beta \pi_{\mathrm{j}}+\delta C T_{l}^{j}+(1-\delta) C T_{w}^{j} \geq 0$

Firm $\mathrm{j}$ will be willing to pay firm $\mathrm{i} \theta$ in order to solve the problem privately if, and only if:

$\beta \pi_{j}(1+\delta)+\delta C T_{l}^{j}+(1-\delta) C T_{w} \geq \theta+T C$

(where $\mathrm{TC}$ is the cost of bargaining for a private agreement, which is assumed to be paid by firm $\mathrm{j}$ ).

Then, replacing $\theta$ from equation (5) into (8) and assuming $\mathrm{CT}_{\mathrm{w}}{ }^{\mathrm{j}}=\mathrm{CT}_{\mathrm{w}}{ }^{\mathrm{i}}=\mathrm{CT}_{\mathrm{w}}$ and $\mathrm{CT}_{1}^{\mathrm{j}}=\mathrm{CT}_{1}^{\mathrm{i}}=\mathrm{CT}_{1}$, and solving for $\pi_{\mathrm{j}}$, we obtain:

$\pi_{j}=\frac{\alpha \delta}{\beta(1+\delta)} \pi_{i}-\left[\frac{C T_{l}+C T_{w}-T C}{(1+\delta) \beta}\right]$

From (4) and (9) we can graph both decision functions for each player (Picture A1). For equation (9), in Picture $\mathrm{A} 1$, in point $\mathrm{A}, \pi_{\mathrm{i}}$ is equal to zero.

$\pi_{i}=0 \Rightarrow \pi_{j}=\frac{-\left(C T_{l}+C T_{w}-T C\right)}{(1+\delta) \beta}$

In point $\mathrm{B}$, equation (9) is equal to equation (4).

$\pi_{j}=\frac{\alpha}{\beta}\left[\frac{\delta C T_{w}+(1-\delta) C T_{l}}{(1+\delta) \alpha}\right]-\left[\frac{C T_{l}+C T_{w}-T C}{(1+\delta) \beta}\right]$

Solving,

$\pi_{j}=\frac{-(1-\delta) C T_{w}-\delta C T_{l}+T C}{(1+\delta) \beta}<0$

Finally, in point $\mathrm{C}, \pi_{\mathrm{j}}$ is equal to zero, then:

$\pi_{i}=\frac{C T_{l}+C T_{w}-T C}{\delta \alpha}$ 


\section{Figure A1}

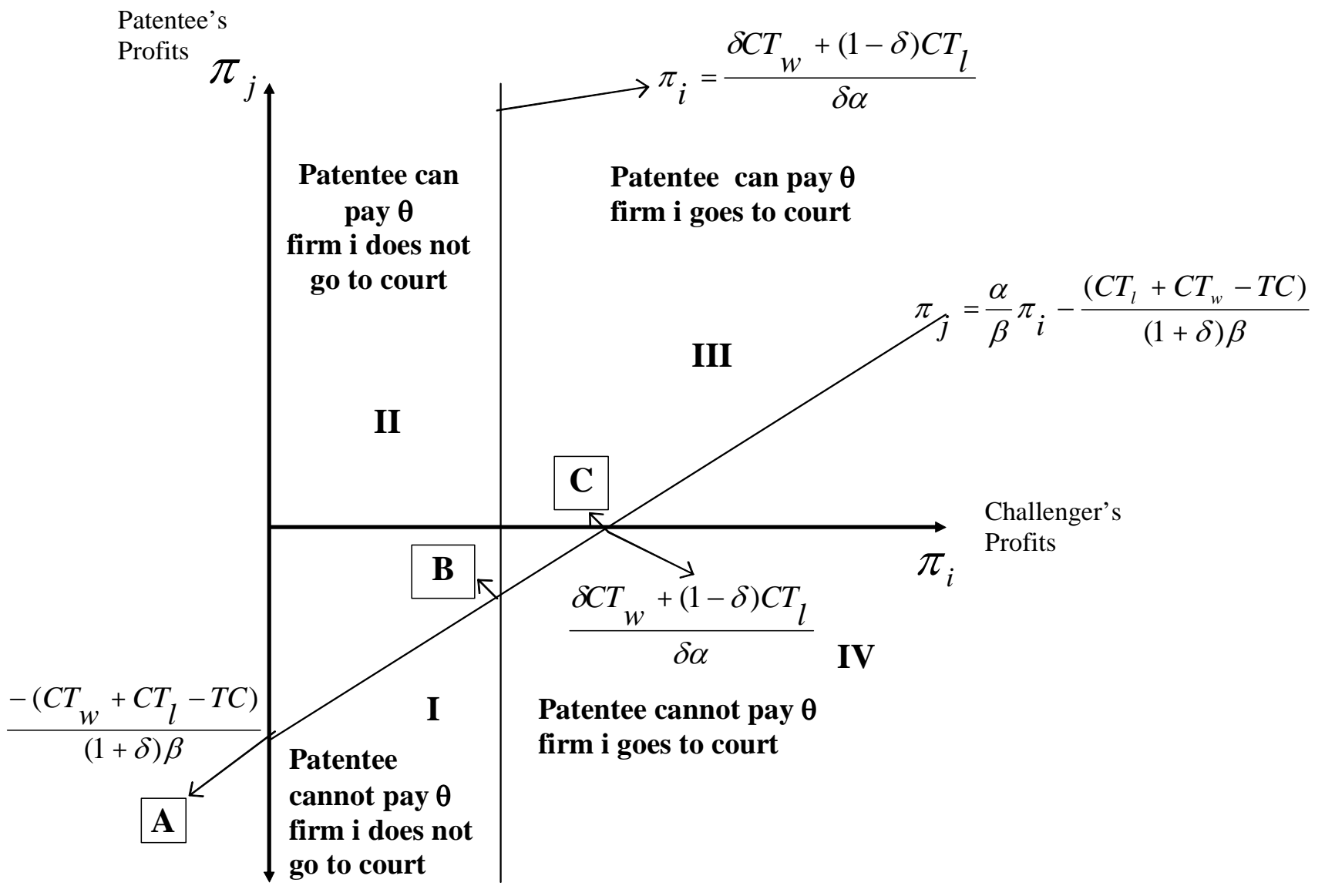




\section{B. Static Comparative}

In this section, we study how changes in litigation costs, the probability of winning the trial and the private costs affect each curve and the area for each type of result.

\section{Litigation Costs}

$\frac{\partial \pi_{j}}{\partial C T_{l}}=\frac{\partial \pi_{j}}{\partial C T_{w}}=\frac{-1}{(1+\delta) \beta}<0$

$\frac{\partial \pi_{i}}{\partial C T_{w}}=\frac{1}{\alpha}>0$

$\frac{\partial \pi_{i}}{\partial C T_{l}}=\frac{(1-\delta)}{\delta \alpha}>0$

Graphically,

\section{Figure A2}

Patentee's Profits

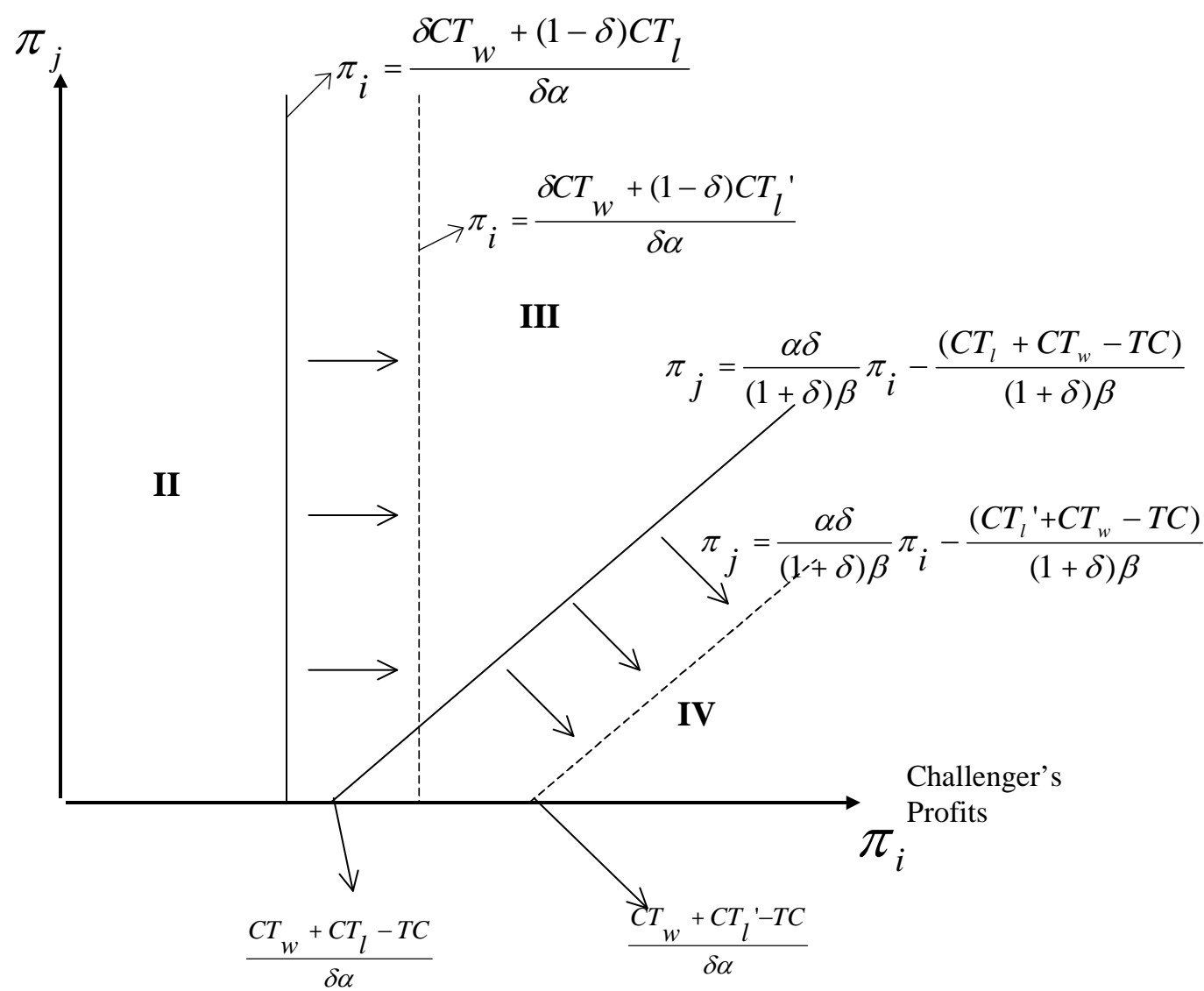


From Figure A2 we can see that Area II increases and Area IV decreases. The effect over Area III of an increase in litigation costs is mixed. In order to evaluate such change we should compare the increase in area III, rectangle A, with the corresponding reduction in the same area, parallelogram B (Figure A3).

\section{Figure A3}

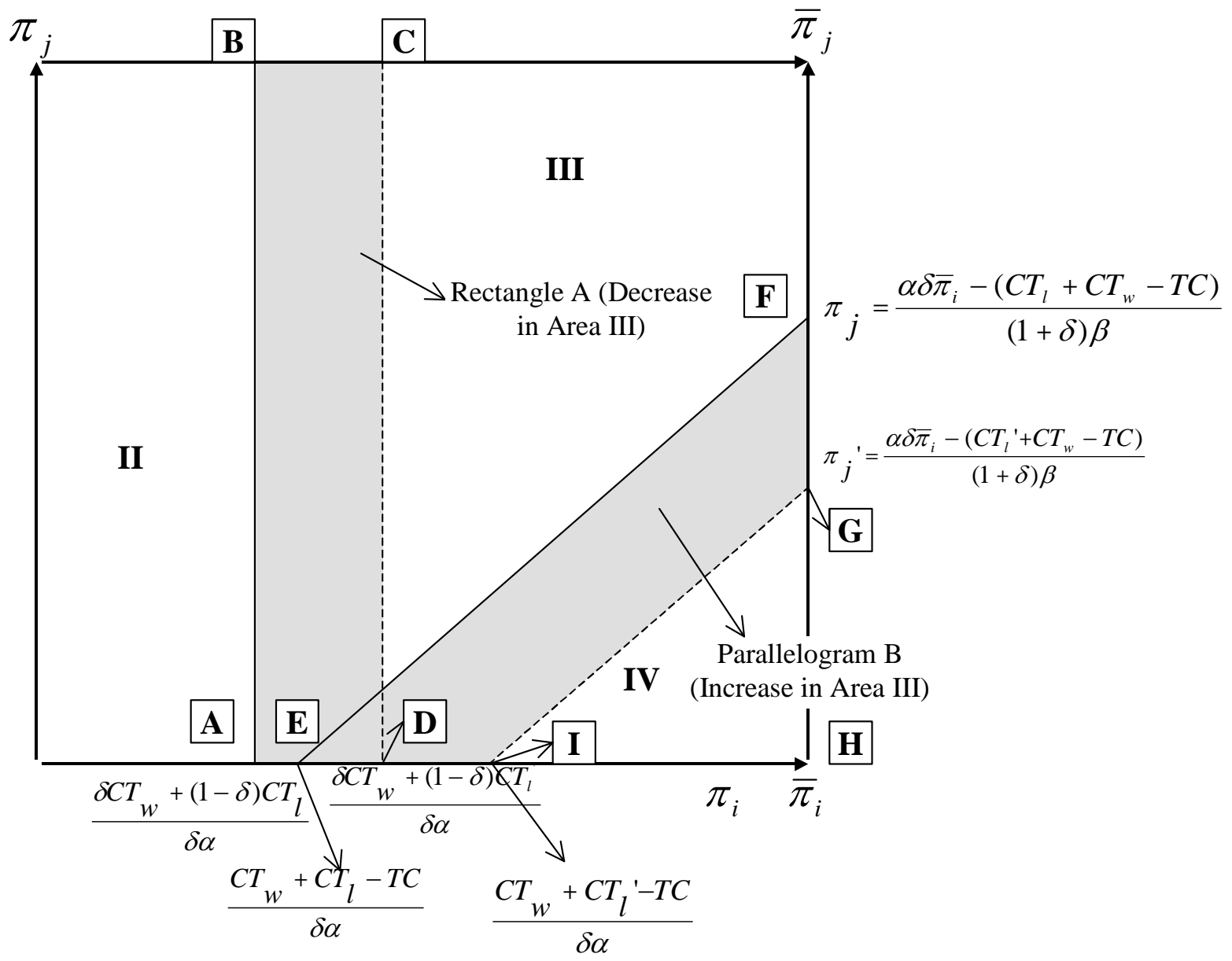

The area of parallelogram B can be expressed as the difference between two triangles, EFH - IGH, which is equal to:

$E F H-I G H=\frac{\left(C T_{l}{ }^{\prime}-C T_{l}\right)}{\beta(1+\delta)}\left[\bar{\pi}_{i}-\frac{\left[2 C T_{w}-2 T C+C T_{l}{ }^{\prime}+C T_{l}\right]}{2 \alpha \delta}\right]>0$

Rectangle area ABCD can be expressed as, 
$A B C D=\left[\frac{(1-\delta)\left(C T_{l}^{\prime}-C T_{l}\right)}{\delta \alpha}\right] \bar{\pi}_{j}$

Now, we should compare both areas in order to determine the sign of the change in Area III:

$(E F H-I G H)-A B C D=\left(C T_{L}^{\prime}-C T_{L}\right)\left[\frac{\bar{\pi}_{i}}{(1+\delta) \beta}-\frac{(1-\delta) \bar{\pi}_{j}}{(1+\delta) \beta \alpha \delta}+\frac{C T_{w}-T C+C T_{l}+C T_{l}^{\prime}}{(1+\delta)}\right]$ (17)

This expression could be either positive or negative. If it is greater than zero, then area III will increase, and there will be more agreements. Similarly, an increase in litigation costs will increase the number of incorrectly issued patents which are not contested in court (Case II). This will increase the number of incorrectly issued patent that are resolved privately (Case III) and will decrease the number of incorrectly issued patents contested in courts (Case IV). If, however, the expression is less than zero, there will be less private agreement than before the change in litigation costs. As a consequence, both the number of patents contested in courts (Case IV) and the number of patents agreed to privately (Case III)

decrease due to higher litigation costs.

\section{Court Performance}

How will the different strategies be affected by a change in the probability of the court rejecting a "bad" patent, i.e., a change in the parameter $\delta$ ?

For firm j:

$$
\frac{\partial \pi_{j}}{\partial \delta}=\frac{\alpha \beta \pi_{i}+\beta\left(C T_{l}+C T_{w}-T C\right)}{(1+\delta)^{2} \beta^{2}}>0
$$

For firm i:

$$
\frac{\partial \pi_{i}}{\partial \delta}=\frac{\alpha C T_{l}}{(\delta \alpha)^{2}}<0
$$

Graphically, 


\section{Figure A4}

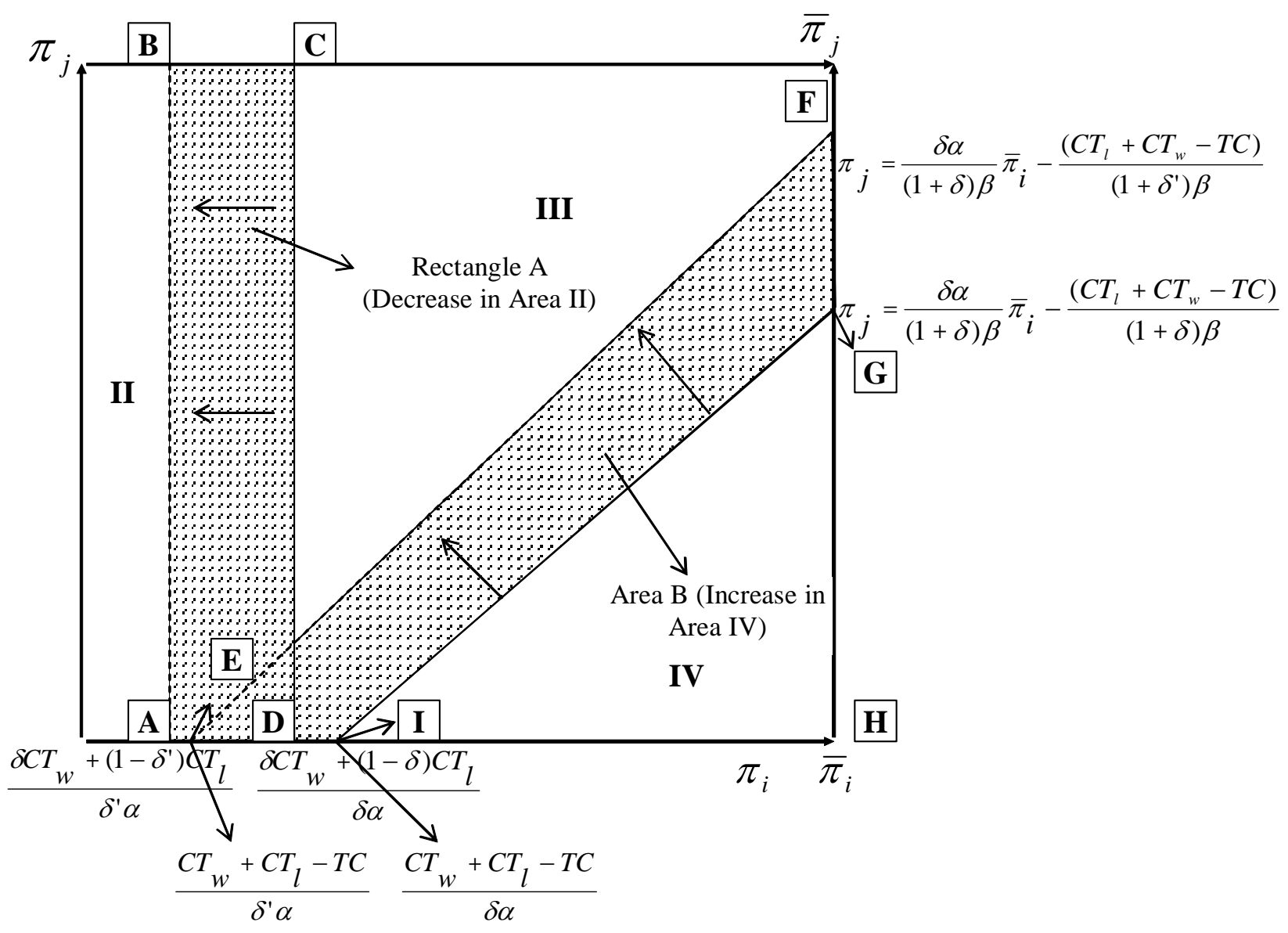

Area IV increases, i.e., there are more "bad" patents contested in court. Area II declines, i.e., fewer "bad" patents are not contested. The change in Area III is undetermined.

\section{Private Cost of Bargaining}

What is the effect of an increase in CT, the cost of reaching a private solution before going to court?

$\frac{\partial \pi_{j}}{\partial T C}=\frac{1}{(1+\delta) \beta}>0$

$\frac{\partial \pi_{i}}{\partial T C}=0$ 
Graphically,

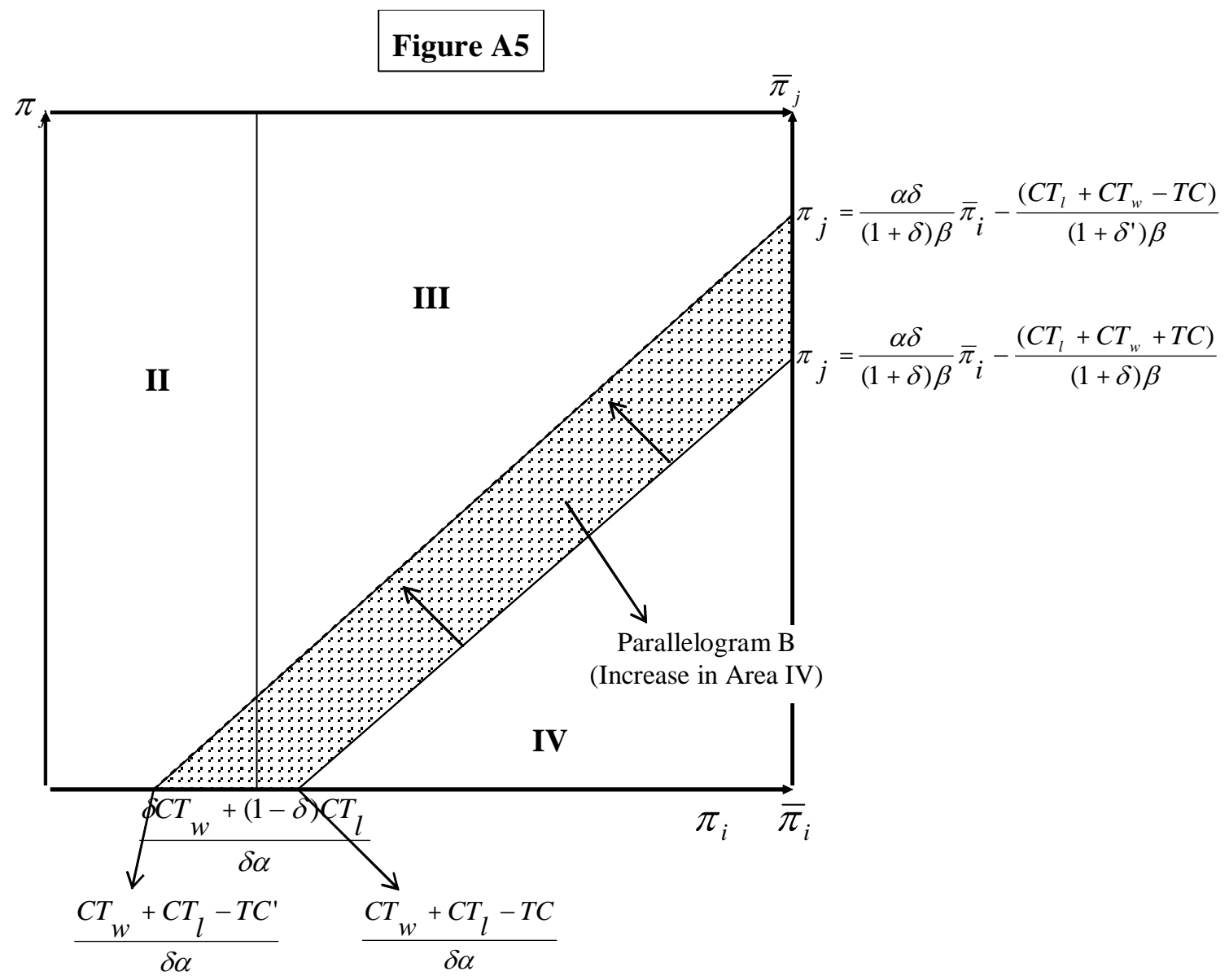

In this case, more "bad" patents are going to court. 


\section{APPENDIX B}

\section{The Model}

Given the model described in the previous section, in this section we analyze the payoffs generated by the different equilibria and describe each possible result.

Result 1: Firm i does not challenge the validity of the patent. Accordingly, firm i will have to pay licensing fees to the patentee if it chooses to use the technology. The payoffs of such a result are given by:

$E P_{i}^{1}=0$

$$
E P_{j}^{1}=\beta \pi_{j}
$$

Result 2: Firm i decides to challenge the patent, there is no private agreement offer from firm j, and firm i does not go to court. In this case, the expected payoff for each firm is:

$E P_{i}^{2}=\gamma\left(\alpha \pi_{i}-C T_{A L}\right)+(1-\gamma)\left(-C T_{A L}\right)$

$E P_{j}^{2}=\gamma\left(-\beta \pi_{j}-C T_{A L}\right)+(1-\gamma)\left(-C T_{A L}\right)$

where:

$\gamma$ is the probability the PTO revokes the patent; $\mathrm{CT}_{\mathrm{AL}}$ is the cost of using the opposition system provided by the Patent Office.

Without loss of generality, we assume this cost is the same for both parties.

Result 3: Firm i challenges the patent. There is no private agreement offer, but firm i decides to go to court instead of risking losing a challenge with the Patent Office or in case it loses a challenge in the Patent Office.

$E P_{i}^{3}=\gamma\left(\alpha \pi_{i}-C T_{A L}\right)+(1-\gamma)\left[\delta\left(\alpha \pi_{i}-C T_{w}\right)+(1-\delta)\left(-C T_{L}-C T_{A L}\right)\right]$

$E P_{j}^{3}=\gamma\left(-\beta \pi_{j}-C T_{A L}\right)+(1-\gamma)\left[\delta\left(-\beta \pi_{j}-C T_{L}-C T_{A L}\right)+(1-\delta)\left(-C T_{w}\right)\right]$

We assume that in the event of winning the trial in court, the cost of using the PTO (Patent Office) is refunded to the winning party. As another alternative, this cost could be charged to the PTO (Patent Office) as a disincentive/penalty for producing wholly non-persuasive decisions.

Result 4: Firm $\mathrm{i}$ challenges the patent, firm $\mathrm{j}$ offers a private agreement, and firm $\mathrm{i}$ will not go to court if it loses the opposition. 
$E P_{i}^{4}=\theta_{A} \quad$ (if firm i accepts the agreement)

$E P_{i}^{4}=\gamma\left(\alpha \pi_{i}-C T_{A L}\right)+(1-\gamma)\left[-C T_{A L}\right] \quad$ (if firm i does not accept the agreement)

$E P_{j}^{4}=\beta \pi_{i}-\theta_{A}-T C \quad$ (if firm i accepts the agreement)

$E P_{j}^{4}=\gamma\left(-\beta \pi_{j}-C T_{A L}\right)+(1-\gamma)\left[-C T_{A L}\right]$ (if firm i does not accept the agreement)

Where, $\theta_{\mathrm{A}}$ is the private agreement firm $\mathrm{j}$ has to pay in order to avoid going to the opposition system.

Result 5: Firm i challenges the patent, firm $j$ offers a private agreement and firm $i$ goes to court after having lost in the Patent Office.

$E P_{i}^{5}=\theta_{B} \quad$ (if firm $i$ accepts the agreement)

$E P_{i}^{5}=\gamma\left(\alpha \pi_{i}-C T_{A L}\right)+(1-\gamma)\left[\delta\left(\alpha \pi_{i}-C T_{w}\right)+(1-\delta)\left(-C T_{L}-C T_{A L}\right)\right]$

(if firmi does not accept the agreement)

$E P_{j}^{5}=\beta \pi_{i}-\theta_{B}-T C \quad$ (if firm i accepts the agreement)

$E P_{j}^{5}=\gamma\left(-\beta \pi_{j}-C T_{A L}\right)+(1-\gamma)\left[\delta\left(-\beta \pi_{j}-C T_{A L}-C T_{L}\right)+(1-\delta)\left(-C T_{w}\right)\right]$

(if firm i does not accept the agreement)

Where $\theta_{\mathrm{B}}$ is the private agreement to be paid by firm $\mathrm{j}$ in this case.

Given the expected payoffs in each situation, we should analyze the different strategies of the players with respect to the different courses of action taken. First, firm i must decide whether or not it is optimal to initiate an opposition, and then subsequently, whether or not it is optimal to go to court. In its decision of whether or not to challenge the patent using the PTO (Patent Office) system, firm i has to compare the expected payoff of result 1 with the expected payoff of result 2 . Comparing the expected payoff in 1 with respect to 2 , we obtain:

$\pi_{i}=\frac{C T_{A L}}{\alpha \gamma}$

If the total benefit is greater than the right side of equation (6), firm i will prefer to resort to the Patent Office opposition system. Otherwise, firm i will not challenge the patent, and the optimal strategy will be to pay for the use of the technology. By comparing the expected payoff in result 2 , when firm $\mathrm{i}$ initiates an opposition but does not go to court, with the expected payoff in 3 , when firm i goes to court, we find that:

$\pi_{i}=\frac{-\delta C T_{A L}+\delta C T_{w}+(1-\delta) C T_{l}}{\delta \alpha}$

In this case, if the benefit to firm $i$ is greater than the right side of equation (7), then firm i will prefer to go to court instead of risking losing the Patent Office 
opposition. $^{134}$ Otherwise, it will prefer not to go to court. The minimum level of benefit required to make court an optimal solution increases with the probability of winning the opposition and any subsequent court trials. Based on our assumptions, the minimum level from equation (7) is greater than equation (6).

Figure 9 shows the three areas of decision for firm i. In the first region, firm i's optimal decision is to leave the patent without challenge. In the second region, the optimal strategy is to let the Patent Office decide the validity of the patent without going to court. Finally, in the third area, the patent is challenged in both the Patent Office and the courts. Challenging the patent will depend on the size of the profits firm $i$ would lose by the existence of the patent and the costs of resorting to the opposition system and to the courts.

For firm $\mathrm{j}$, we should evaluate the decision of whether or not to offer a private agreement to firm i. Accordingly, we should compare results 2 and 4, in which firm i is not going to court, and results 3 and 5, in which firm i's optimal strategy is to resort to court. In the first case, we compare the expected payoff for firm $\mathrm{j}$ in case 2 with the expected payoff in case 4 :

$$
E P_{j}^{2}=\gamma\left(-\beta \pi_{j}-C T_{A L}\right)+(1-\gamma)\left(-C T_{A L}\right)=\beta \pi_{i}-\theta_{A}-T C=E P_{j}^{4}
$$

If the left side of equation (8) is greater than the right side, then the optimal strategy for firm $\mathrm{j}$ is not to offer a private agreement. Otherwise, it will be optimal to agree privately with firm i. By solving equation (8), we obtain the following expression:

$$
(1+\gamma) \beta \pi_{j}=\theta_{A}+T C-C T_{A L}
$$

Now, if the left side is greater than the right side, it is optimal to offer a private agreement. We should obtain an expression for $\theta_{\mathrm{A}}$, the required payment firm $\mathrm{j}$ has to make to firm $i$ in order to make the private agreement possible. In case 4, the payment is obtained by comparing the expected payoffs with and without a private agreement for firm $\mathrm{i}$ :

$\theta_{A}=\gamma\left(\alpha \pi_{i}-C T_{A L}\right)+(1-\gamma)\left[-C T_{A L}\right]$

Solving this equality for $\theta_{\mathrm{A}}$ :

$\theta_{A}=\gamma \alpha \pi_{i}-C T_{A L}$

Equation (11) suggests that firm i will accept a private agreement when the payment from firm $\mathrm{j}$ is greater than or equal to expression (11). Substituting equation (11) into equation (9) and solving, produces the following condition for firm j payoff:

$$
\pi_{j}=\frac{\gamma \alpha \pi_{j}-2 C T_{A L}+T C}{(1+\gamma) \beta}
$$

When the total profit for firm $\mathrm{j}$ is greater than or equal to equation (12), it is optimal to offer a private agreement to firm i. This avoids the initiation of a Patent Office opposition process.

134. If we compare the expected result of not going to court, in result 4, with the expected payoff of going to court, in result 5 , we obtain the same result as in equation (16). 
In the second case, firm $\mathrm{j}$ has to evaluate if it is optimal to offer a private agreement to firm $i$, given that it is optimal for firm $i$ to go to court in addition to going to the Patent Office opposition system. Therefore, we should compare the expected payoff for firm $\mathrm{j}$ in case 3 , when there is no agreement, with case 5, where firm $\mathrm{j}$ offers a private agreement. Comparing the expected payoffs for firm $\mathrm{j}$ in case 3 and 5, we obtain:

$$
\begin{aligned}
& E P_{j}^{3}=\gamma\left(-\beta \pi_{j}-C T_{A L}\right)+(1-\gamma)\left[\delta\left(-\beta \pi_{j}-C T_{L}-C T_{A L}\right)+(1-\delta)\left(\beta \pi_{j}-C T_{w}\right)=\right. \\
& \beta \pi_{j}-\theta_{B}-T C=E P_{j}^{5}
\end{aligned}
$$

If the left side of equation (13) is greater than the right side, then it is optimal for firm $\mathrm{j}$ not to offer a private agreement. Otherwise, it is optimal to agree with firm $\mathrm{i}$ instead of resorting to either the Patent Office or the courts. Simplifying expression (13) produces:

$$
-C T_{A L}(\delta+(1-\gamma) \delta)-(1-\gamma)\left[\delta C T_{L}+(1-\delta) C T_{w}\right]+\theta_{B}+T C=\beta \pi_{j}(1+\gamma+\delta-\delta \gamma)
$$

In this case, we should obtain a solution for $\theta_{\mathrm{B}}$ by comparing the expected payoff for firm $\mathrm{i}$, in case 5 , with and without private agreement:

$$
E P_{i}^{5}=\theta_{B}=\gamma\left(\alpha \pi_{i}-C T_{A L}\right)+(1-\gamma)\left[\delta\left(\alpha \pi_{i}-C T_{w}\right)+(1-\delta)\left(-C T_{L}-C T_{A L}\right)\right]=E P_{i}^{5}
$$

Solving equation (15) for $\theta_{\mathrm{B}}$, we obtain:

$$
\left.\theta_{B}=\alpha \pi_{i} \delta+(1-\gamma) \delta\right)-(1-\gamma)\left[\delta C T_{w}+(1-\delta) C T_{L}\right]-C T_{A L}(1-\delta+\delta \gamma)
$$

Substituting equation (16) into equation (15) and solving for the level of profit for firm $\mathrm{j}$ produces:

$$
\pi_{j}=\frac{\alpha \delta(2-\gamma) \pi_{i}-(1+\gamma) C T_{A L}-(1-\gamma)\left[C T_{L}+C T_{w}\right]+T C}{\beta(1+\gamma+\delta-\delta \gamma)}
$$

Equation (17) suggests that firm $\mathrm{j}$ will offer a private agreement when the total profit is greater than or equal to the right side of the expression. Otherwise, firm $\mathrm{j}$ will prefer to wait on the Patent Office and court decisions. With these equations, we have enough instruments to determine the different equilibria for our model. Figure 10 illustrates the decision curves for firm $\mathrm{i}$ and $\mathrm{j}$, as expressed by equations (6) and (7) for firm $i$ and (12) and (17) for firm j. Figure 10 suggests that the set of equilibria becomes more complex than in our previous situation without a Patent Office opposition system. With the opposition system, the optimal strategies for firm $\mathrm{j}$ are depicted by two curves, representing equations (12) and (17). In the areas above each of these curves, firm j's optimal strategy is to offer a private agreement Below any of these curves, the optimal decision is to let the Patent Office or the court decide the dispute. When firm i does not go to court, equation (12) represents firm j's decision curve (in Figure B1, it is the curve with the higher profit level). But, when firm i decides to resort to the courts, equation (17) represents the decision curve for firm $\mathrm{j}$ (in Figure B1, this is the lower curve). 


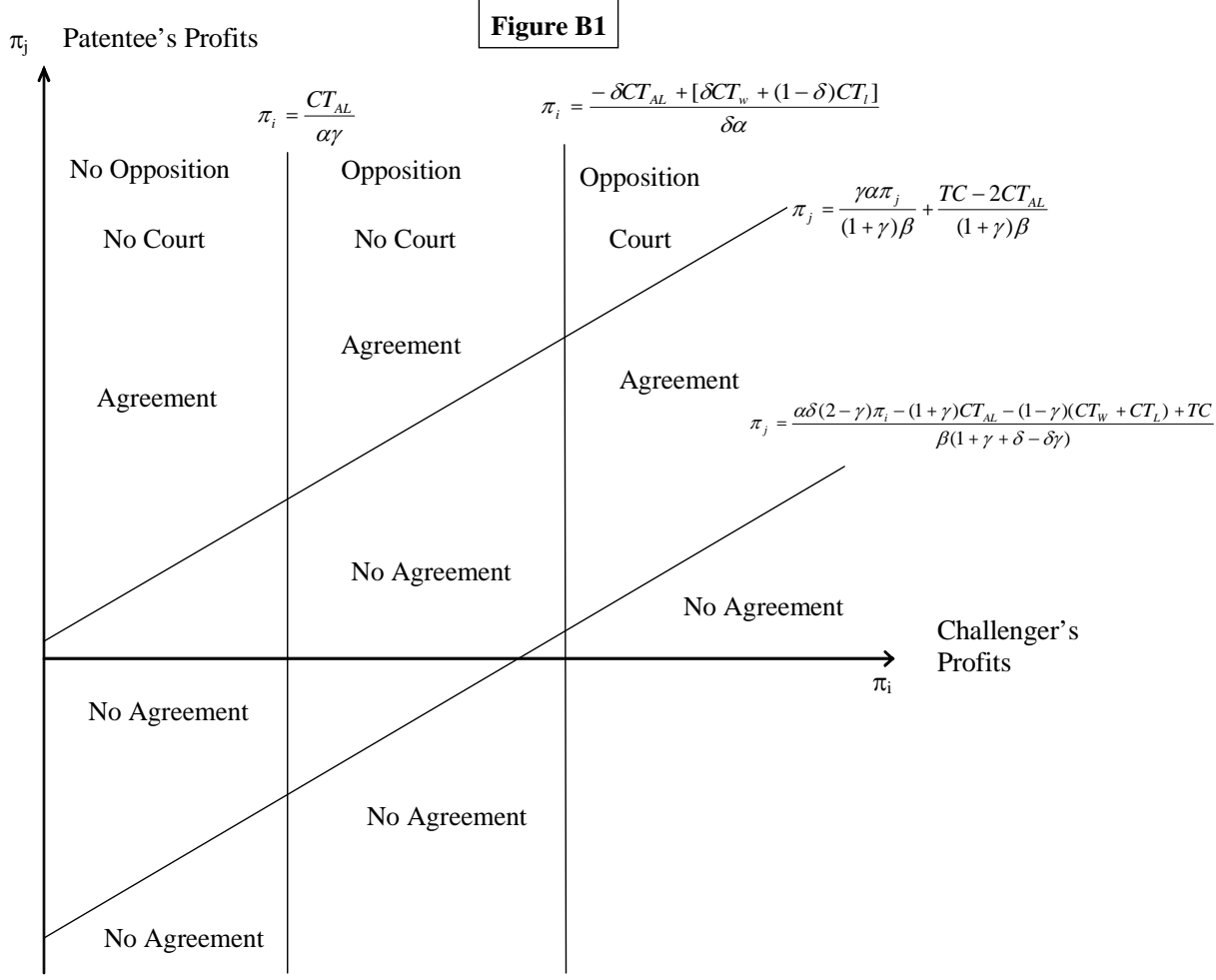

